\title{
The tone from above: The effect of communicating a supportive regulatory strategy on reporting quality
}

\author{
SANNER \\ SANNE R. VAN DUIN*, HENRI C. DEKKER* , JACCO L. WIELHOUWER*, \\ JUAN P. MENDOZA* \\ The tone from above: The effect of communicating a
supportive regulatory strategy on reporting quality
}

\begin{abstract}
:
\end{abstract}
In collaboration with the Authority for the Financial Markets in the Netherlands, we manipulate the content of official letters that instruct financial intermediaries to submit a mandatory self-assessment. As part of the Registered Report Process, we submitted our hypotheses, experimental procedure, and planned statistical analyses before data collection. We predicted that a request indicating a supportive regulatory attitude has a positive effect on reporting quality on average. We also predict this effect to be stronger for small firms and for firms with a long-term orientation, and to become negative for firms with a short-term orientation. Planned analyses show that a supportive letter reduced reporting quality unless firms had a long-term orientation, supporting the moderating influence of time horizon, but providing no support for the expected average effect nor for moderation by firm size.

JEL Classification: G28, M48, K42

Keywords reporting quality, responsive regulation, support, time horizon

${ }^{*}$ School of Business and Economics, Vrije Universiteit Amsterdam.

Accepted by Robert Bloomfield. This paper is the final Registered Report resulting from the Registration-based Editorial Process (REP) implemented by JAR for its 2017 conference; details of the process are available here https://research.chicagobooth.edu/-/media/research/arc/docs/journal/rep_policies jar.pdf. The accepted proposal and Online Appendices for this report are available at https://research.chicagobooth.edu/arc/journal-ofaccounting-research/online-supplements.

We thank the Authority for Financial Markets in the Netherlands for participating in this study and providing us access to the data. The data that were collected as part of this study are proprietary and cannot be shared. We thank the anonymous reviewer for helpful suggestions throughout the Registered Report Process. We explicitly notify that all statements and opinions in this article reflect those of the authors, not of the Authority for Financial Markets. Authors did not receive any compensation (in any form) for conducting the study and for providing advice based on the results.

This is the author manuscript accepted for publication and has undergone full peer review but has not been through the copyediting, typesetting, pagination and proofreading process, which may lead to differences between this version and the Version of Record. Please cite this article as doi:

$\underline{10.1111 / 1475-679 X .12205 .}$.

This article is protected by copyright. All rights reserved. 


\section{Introduction}

Across diverse regulatory settings, authorities request proprietary information from firms as part of their monitoring and supervision strategies. This is particularly relevant in contexts in which there is a significant information gap between the firm and the authority (Besanko and Sappington [1987], Pautz and Rinfret [2016]). In the contexts of tax, customs, financial, or envirommental regulations, for instance, firms are commonly requested to complete and submit mandatory self-assessments in which they report sensitive information. Evidently, the effectiveness of the authorities' supervision strategies directly depends on the quality of the information that firms provide (Peeters [2006]). Imprecise, incomplete, or untimely information obstructs monitoring and makes supervision more difficult, time consuming, and costly.

Self-reporting commonly involves a series of actions, which include gathering detailed information, completing extensive questionnaires, and meeting tight deadlines (Ernst \& Young [2012]). The quality of the information reported to the authorities is determined by these actions, as they directly influence precision and comprehensiveness, as well as the extent to which firms voluntarily report additional information. In this sense, reporting quality can be conceptualized as a behavioral outcome that depends on firms' motivation and capacity to attain high reporting quality.

Because effective supervision benefits greatly from high reporting quality, a fundamental question is whether authorities can exert influence to improve reporting quality. This is a non-triviat problem, as it may not be sufficiently addressed through deterrence (i.e., by threatening firms with penalties for not reporting information with the highest level of quality). Firms may comply with minimum reporting requirements, and yet provide low reporting quality (e.g., by reporting approximate figures). Establishing whether low reporting quality sufficiently reflects reality - and whether it deserves a punishment - imposes additional_challenges for the authorities. From a supervisory standpoint, the core problem is that authorities may explicitly request the highest level of reporting quality, but in practice may have limited resources to monitor and assess the level of reporting quality itself.

Following the literature on responsive regulation (Braithwaite [2003, 2007]), one way in which authorities might be able to influence reporting quality is by signaling a supportive regulatory strategy towards firms. The rationale is that, as the strategy focuses more on 
guidance and support, firms' motivations to attain high reporting quality increase. The concept of responsive regulation establishes that there are distinct types of regulatory strategies, which vary in terms of how supportive they are (Braithwaite [2007]). A strategy that focuses less on deterrence and more on education and service-delivery motivates firms to share information. Moreover, an educational approach helps firms to "make sense" of what is requested from them and encourages compliance (Fairman and Yapp [2005]). In this sense, support enhances the perception that the authority is fair and trustworthy, and prompts reciprocity from at least a fraction of supervised firms (Alford and Speed [2006]). Overall, there are distinet reasons to expect a positive effect of a supportive strategy on how firms respond to the authority's requests, including the request to provide high quality information.

Because not all firms can be visited at the same time, authorities have limited options to present themselves as helpful and exert this type of supportive influence at an industry-wide scale. For a large number of firms, interactions with the authority are constrained to infrequent official communications (in the form of formal letters). Taking this point into consideration, in this study we examine whether reporting quality is influenced by the extent to which official communications reflect a supportive regulatory strategy. Our hypothesis is that, as compared to a low support letter, a high support letter leads to higher reporting quality. We acknowledge, however, that the strength of the expected effect may vary depending on firms' specific characteristics and motivations (Braithwaite [2003, 2007]). Hence, we further hypothesize that the expected effect is weaker for larger firms (which might be less sensitive to the content of official communications), stronger for long-term oriented firms (which might see reporting quality as an investment), and reversed for shortterm oriented firms (which might perceive support as a signal of a weaker enforcement strategy and seize the opportunity to report low quality information).

To test these hypotheses, we conduct a field experiment in the regulatory setting of financial intermediation in the Netherlands. The Authority for the Financial Markets (AFM), which supervises the financial markets and financial services providers in this country, granted us permission to introduce an experimental treatment in their 2017 communications. The AFM employs a supervision instrument called Market Monitor, which is a mandatory, standardized self-assessment instrument and is sent out to approximately 7,000 financial intermediaries on a yearly basis. Through this instrument, firms provide an elaborate amount 
of sensitive information related to, for example, financial products offered, specific financial intermediation activities, number of employees and customer relationships, as well as detailed accounting and managerial information. Every year, the AFM sends three letters to each firm providing information on how to complete and when to submit the Market Monitor.

Based on prior experience, the AFM recognizes that intermediaries vary in the amount and precision of the information that they report. After a series of discussions with the AFM, it was jointly determined that there are valid reasons to expect that the quality of the reported information can be influenced by the content of the letters in which firms are instructed to complete and submit the Market Monitor. As a result, we designed a field experiment in which we employ two distinct sets of letters (which contain information about the instructions, username, and password required to complete the Market Monitor), and which reflect a regulatory strategy based on low vs. high support. We identify three elements that relate to support, and which can be manipulated in order to influence firms' perceptions and reporting behavior. These elements are: accessibility (absence of obstacles or barriers to ask for help or guidance), purpose (goal alignment between the authority and the firm), and tone. High support letters emphasize that the regulator is accessible to provide support on how to complete the Market Monitor, identify shared goals, and have a supportive tone. In contrast, low support tetters only indicate where to find information without expressing the willingness of the regulator to provide support, do not identify shared goals, and have a strict tone. Our objective is to compare the effects that each set of letters has on reporting quality, as indicated by comprehensiveness, precision ${ }^{1}$, and voluntary provision of information (i.e., answering non-mandatory questions). In addition, we examine how the strength of this effect varies with firm size and time horizon. As part of the Journal of Accounting Research Registered Report Process, we submitted our hypotheses, experimental procedure, and planned statistical analyses before collecting the data.

Examination of the data as proposed provides partial support for one of our hypotheses: the high support letter leads to lower reporting quality except for long-term oriented firms. Long-term oriented firms (i) on average provide higher reporting quality than small- and medium-term oriented firms, and (ii) as compared to those firms, show no decrease in reporting quality after receiving a high support letter. In addition, planned additional tests

\footnotetext{
1 In our proposal, we used the term "accuracy" for this construct. However, the term "precision" better fits our operationalization of the construct.
} 
incorporating the extensiveness instead of use of voluntary reporting reveal an antagonistic interaction effect: the high support letter has a positive (negative) effect for firms with a long (short) time horizon. This effect supports our third hypothesis, and goes in line with the idea that industry-wide interventions have heterogeneous effects, which vary across different firm types. While short-term oriented firms may negatively exploit support by reducing reporting quality, a long-term orientation appears to prevent such exploitation from happening and even enhance the hypothesized positive effect of support on reporting quality. These results can guide regulators on how to target data quality checks, and differentiate regulatory strategy, actions, and official communications based on firms' characteristics.

This study contributes to the literature in several ways. In the empirical accounting literature, reporting quality is typically examined with respect to financial accounting reports, using publicly ayailable data (e.g., Balakrishnan, Core and Verdi [2012], Biddle, Hilary and Verdi [2009]). In contrast, we examine reporting quality in a regulatory context where firms face the compulsory demand to self-report sensitive information to an authority. Analyses of regulatory reporting are uncommon, likely due to difficulties in obtaining access to sensitive and confidential data. Similar to the argument that financial reporting quality reduces information asymmetry with investors (Balakrishnan et al. [2012]), high reporting quality reduces the information asymmetry with the authority, enabling it to better fulfill its objective of regulatory oversight.

A second contribution relates to how authorities may be able to influence firms' reporting quality. In a setting with infrequent contact with firms, communicating a particular regulatory strategy can have significant impact on reporting behavior. This highlights the importance of the way in which authorities present themselves in official communications. We identify an important boundary condition for the effect of the high support letter, as it is conditional on firms' time horizon. Our results show that time horizon is critical in how firms respond to regulatory requests and whether a support-based approach is effective or even backfires.

Regulators are generally reluctant to participate in field experiments given the political sensitivity and magnitude of the responsibility associated with using differential treatments between firms. However, there is great value in examining these types of questions in regulatory practice, as there is uncertainty on whether regulation-related questions are 
suitable for lab experiments (Choo, Fonseca and Myles [2016], Lindeboom, Van der Klaauw and Vriend [2016]). Prior field experiments on regulatory strategies have focused primarily on tax reporting, testing whether communications reflecting particular regulatory strategies affect tax compliance. These experiments mainly include theory-based manipulations related to deterrence and support, such as varying monitoring or punishment levels (Blumenthal, Christian and Slemrod [2001], Wenzel and Taylor [2004], Hasseldine, Hite, James and Toumi [2007], Ariel [2012], Fellner, Sausgruber and Traxler [2013], Hallsworth [2014], Castro and Scartascini [2015]), and normative appeals and social persuasion (Ariel [2012]; Hallsworth, List, Metcalfe and Vlaev [2017]; Torgler [2004]). Despite the pervasiveness of self-reporting in ther settings than tax regulation, field experiments in these other settings are rare. This provides much scope for the use of a field experiment to examine the effects of theory-based manipulations on reporting behavior. In this sense, we respond to the recent call for field experiments that examine regulatory effects in practice (Leuz and Wysocki [2016, p.602]).

\section{Theory and Hypotheses}

\section{a.Self-reporting}

There are several reasons why supervisory authorities may be interested in employing self-reporting instruments. Seminal theory in this area indicates that self-reporting can save costs associated with the effective detection of noncompliance, and reduce uncertainty about punishments for both the authority and regulated agents (Kaplow and Shavell [1994], Heyes [2000]). Subsequent theoretical developments have focused on the contexts of tax, environmental, and financial regulations, which are encompassing and permeate a variety of industries A common element across the literature, however, is the emphasis on information asymmetry, whereby authorities have limited access to information about firms' activities and operations (this is also referred to as an information gap; Baron and Myerson [1982], Sappington [1982], Besanko and Sappington [1987], Pautz and Rinfret [2016]). The fundamental problem for authorities is that monitoring is costly, as they have limited capacity and resources to process technical and extensive information in order to effectively assess whether firms are failing to comply with regulations. Self-reporting can help reduce information asymmetries, and in this sense, it can be seen as a complement of a given 
supervisory strategy. As a result, modern regulatory regimes may transfer control and reporting functions to corporate management (referred to as "first instance monitoring"), while the final responsibility for oversight, inspections, and sanctions remains on the side of the authorities (Parker [2002]).

Self-reporting instruments can differ in terms of whether they are mandatory vs. voluntary, periodic vs. sporadic (submitted only upon request), completed and submitted in paper vs. online, or in terms of how extensive and detailed they are. In most cases, however, self-reporting instruments are based on the request of sensitive information, and for this reason, they tend to be treated as confidential. Self-reporting instruments can also have limitations. These mainly relate to potential low response rates (due to, e.g., unclear instructions, incapacity to reach the targeted population, unmeetable requirements or deadlines), untruthful reporting or intentional misreporting (Friesen and Gangadharan [2013]), and low reporting quality (i.e., a level of quality that is insufficient in terms of timeliness, precision, or completeness). Although untruthful reporting has by definition low reporting quality, the distinction between these two potential limitations is fundamental. This is because self-reporting can be truthful, and yet be limited to the bare minimum that is required by law. For example, low reporting quality can involve rough approximations of numerical or date-related responses, and relate to firms' unwillingness to answer nonmandatory questions or provide additional clarifications and perspectives on a voluntary basis (in, e.g., open-ended questions). For supervisory authorities, high reporting quality is therefore the most desirable outcome.

\section{b. Reporting quality as a behavioral outcome}

Self-reporting comprises a series of actions, which broadly relate to properly registering contact information so that the firm can be reached by the authorities, reading and understanding the instructions of the self-reported instrument (on how and when to complete and submit responses), requesting information internally (e.g., to different employees or departments within the firm), aggregating and processing gathered information (e.g., making calculations or synthetizing evaluations), inputting and reviewing responses (by, e.g., board members or heads of departments), and submitting responses on time.

Reporting quality - in terms of precision, comprehensiveness, and the provision of voluntary responses - can be affected by any of the above-mentioned actions, and therefore 
can be conceptualized as a behavioral outcome. As such, reporting quality can be explained by firms' capacity and motivations to strive for high reporting quality.

\section{c. The potential influence of a supportive regulatory strategy}

This study builds on the theory of responsive regulation (Braithwaite [2003, 2007]), which establishes that regulation is more effective when distinct regulatory strategies are properly aligned with corresponding compliance motivations. Regulatory strategies can vary in terms of how intrusive they are. More intrusive strategies rely more heavily on deterrence (involving audits, inspections, punishments, and direct control), whereas less intrusive strategies rely more heavily on persuasion and education (Healy and Braithwaite [2006]). One key objective for the authorities, therefore, is to identify which motivations firms have, and respond accordingly with suitable regulatory strategies.

Firms may have economic and non-economic motivations to comply with regulations (Nielsen and Parker [2012]). Non-economic motivations relate to social or normative considerations (i.e., giving value to the perceptions of significant others or being committed to act responsibly - over and above economic cost-benefit analyses). Abundant research suggests that normative motivations are enhanced by the perception that the authorities' rules and decisions are fair, trustworthy, and legitimate (Malloy [2003], Parker and Nielsen [2011]).

There are several reasons why a supportive strategy fits well into the context of supervision and self-reporting, and may motivate firms to strive for high reporting quality. First, a supportive strategy places particular value on the exchange of information. A regulatory strategy oriented towards education and service-delivery is expected to motivate firms to share information and engage in open dialogue with the authority (Braithwaite [2007]). The foeus is not on detecting wrong-doing, but on using information to attain more important goals. Firms are treated not with suspicion or cold detachment, but rather with respect and in a fair manner (i.e., less as distant regulatees and more as clients or business partners; Alford and Speed [2006], Kirchler, Hoelzl and Wahl [2008]).

Second, the-authority can use this strategy to explain why it needs extensive or detailed information. This is particularly important, as providing explanations about legal requirements and advice on how to implement them helps firms to "make sense" of what is requested from them and encourages compliance (Fairman and Yapp [2005], Mendoza, 
Dekker and Wielhouwer [2016]). For example, the authority can indicate that the information will be used to gain a better understanding of firms' states and needs, and consequently design and implement tools and strategies that better align firms' interests with the interests of the authority and the industry as a whole. Notably, an effective shift from external to internal monitoring requires convincing explanations of why reliable internal diagnostics are useful for both the authority and the firm (e.g., for tracking and improving performance over time; Sinctair [1997]).

A third reason, which follows from the prior two, is that a supportive strategy enhances perceptions of informational fairness (provision of information in a sufficient, clear, and timely manner), procedural fairness (incorporation of firms' perspectives and needs on how to respond to official requests), and interpersonal fairness (treatment of firms with dignity and respect through for example a supportive tone; for a review of fairness dimensions, see Colquitt, Conlon, Wesson, Porter and Yee [2001]). These perceptions enhance the legitimacy of the authority's requests, and increase the willingness to submit and obey on a voluntary basis (Tyler [2006]). Indeed, these perceptions of fairness can lead to reciprocating behaviors of supervised firms (Smith and Stalans [1991], Smith [1992]).

These elements suggest that a supportive regulatory strategy can be used to explicitly recognize and further promote both economic and normative motivations. Firms are better able to identify the material benefits of high reporting quality when they are provided with straightforward explanations of why it is needed and justified (which relates to the outcome of the request). In addition, a supportive regulatory strategy signals that the authority strives for responsiveness, simplicity, and accessibility, and that it cares about the firm and the relationship they share (which relates to the process of how the request is made and handled; Alford and Speed [2006]). By implication, a supportive regulatory strategy involves the respectful and empathic treatment of firms. All these elements have the potential to enhance fairness perceptions and normative motivations to improve reporting quality and to draw attention on its economic value. In terms of social exchange, a strategy based on support, guidance, and service-delivery can be seen as a "gift" from the authority, and may trigger reciprocation from at least a fraction of firms (Alford and Speed [2006]). 


\section{d.Official communications that reflect a supportive regulatory strategy}

Official communications are at the core of a supportive regulatory strategy, especially in the context of self-reporting. They are indicative of the social distance between the authority and the firm (Braithwaite [2003]), and of how the firm is perceived and treated by the authority (e.g., as a suspect vs. a client or business partner; with empathy and respect vs. suspicion and detachment). Furthermore, official communications are a principal mechanism through which a service-delivery approach is materialized at an industry-wide scale, as these communications are needed to properly (i) explain how to obtain materials, tools, and information that firms may require to successfully respond to the authority's request (accessibility);(ii) describe and justify the purpose of the request (goal alignment), and (iii) display a respeetful and open attitude towards the firm (tone). For these reasons, official communications are inherently linked to how firms in general develop perceptions about the regulatory strategy - not only in terms content, but also in terms form, style and tone.

This ogic applies to the specific case of official communications in which the authority explicitly requests high reporting quality, which is the main focus or our analysis. Hence, we state our first hypothesis as follows:

Hypothesis 1: The extent to which official communication reflects a supportive regulatory strategy is positively associated with reporting quality.

\section{$e$. The moderating effects of firm size and firms' time horizon}

Hypothesis 1 predicts average differences in reporting quality between firms that receive communications of different nature. However, there are also arguments against this expectation. In a firm-level - instead of an individual-level - setting, the content of the communication can be ignored or insufficiently noticed by firms, and may therefore have little or no impact on behavior. In addition, regulations in the setting of our experiment (financial intermediation) have expanded and tightened in recent years, so letters reflecting less intrusiveness and more support could be perceived as "soft", diluting the authority's mandate to legally require firms to comply with its requests. One limitation of communicating a supportive regulatory strategy is that it can induce opportunistic behavior, as it relies less on deterrence (Alford and Speed [2006]). Taking these counter-arguments into consideration, we identify two relevant factors that can moderate the expected association between reporting quality and the nature of the communication. 
Firm size. Firm size is indicative of the availability of resources and organizational specialization and professionalism. Reporting and compliance-related tasks are typically performed by owners or high-level managers in smaller firms, and by specialized departments or personnel in larger firms. As firms become larger, reporting tasks are more likely systematic and standardized, and interactions with the authority may be more frequent (due to relative importance in the market). For these reasons, larger firms might be less sensitive to the content of standardized official communications.

One could also argue that compliance officers in larger firms may have relatively more resources available for gathering and reporting information, and that noting a supportive regulatory strafegy could make them walk the extra mile. However, these officers are likely evaluated based on how they avoid issues with - and raise no concerns from - the authorities. Hence, we expect larger firms to have relatively higher reporting quality, independent of the level of support they perceive. Our second hypothesis is depicted in Figure 1, and is stated as follows:

Hypothesis 2: Firm size weakens the positive effect of communicating a supportive regulatory strategy on reporting quality.

The predicted moderation effect of firm size is relevant in practice, as it informs regulators about the possible benefits of customizing their communications for small firms and individuals as compared to larger firms.

Time horizon. This refers to the extent to which firms value future payoffs. It plays a crucial role in inter-temporal decisions, in which costs and benefits are spread out over several periods of time (Loewenstein and Thaler [1989]). Reporting information can be analyzed as an inter-temporal decision-making process. High reporting quality is costly, as it demands time and effort, and thus can be seen as a cost in the short-run, but as an investment in the long-run. This is because high reporting quality can reduce future (expected) costs associated with potential audits and inspections, penalties, and legal disputes, and can also reduce time and expedite the process of gathering, storing, and retrieving information in the future. This goes in-line with the idea that long-term oriented agents value cost-reductions derived from lower supervision, and can thus be monitored to a lesser extent (Mendoza and Wielhouwer [2015]). 
Short-term oriented firms are expected to act in a more opportunistic manner, focusing predominantly on minimizing costs. They may even blame the authority for the circumstances they are in, and perceive regulation as mainly costly and obstructive. This can trigger uncooperative motivational postures towards the authority and its requests (Braithwaite [2003]). But more importantly, short-term oriented firms may interpret a supportive tone as part of a weak enforcement strategy, which is relatively less focused on deterrence and therefore less likely effective in detecting and punishing deviance or noncompliance. These firms may see a supportive regulatory strategy as an opportunity to reduce costs, and assign less value to the potential benefits of attaining high reporting quality and developing a cooperative long-term relationship with the authority. Our third hypothesis is depicted in Figure 1, and is stated as follows:

Hypothesis 3: The positive effect of communicating a supportive regulatory strategy on reporting quality is enhanced by long-term orientation and reversed by (becomes negative with) short-term orientation.

\section{Figure 1. The moderating effects of firm size and time horizon}

Hypothesis 2

\section{reporting}

quality

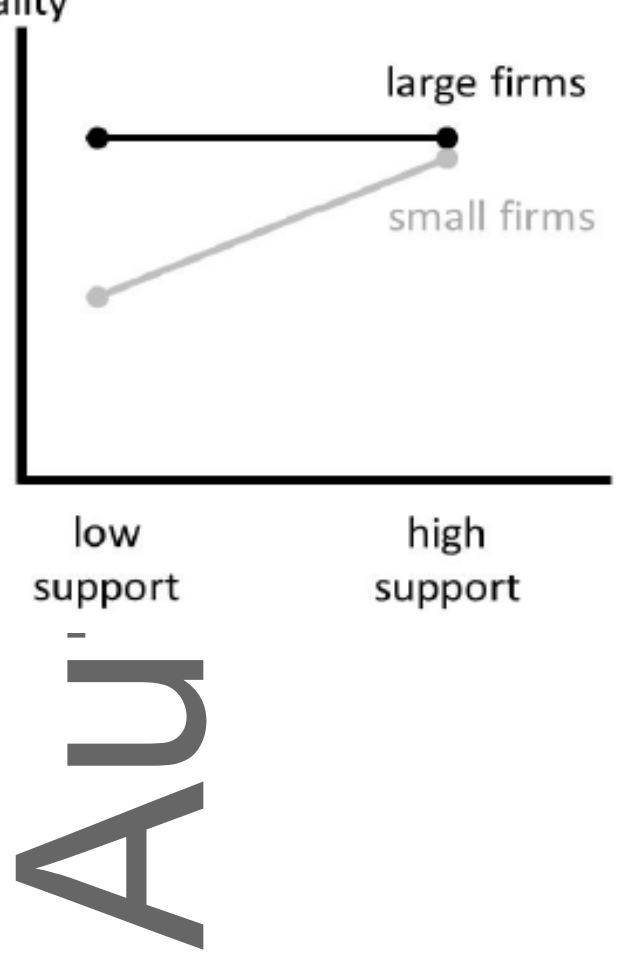

Hypothesis 3

reporting

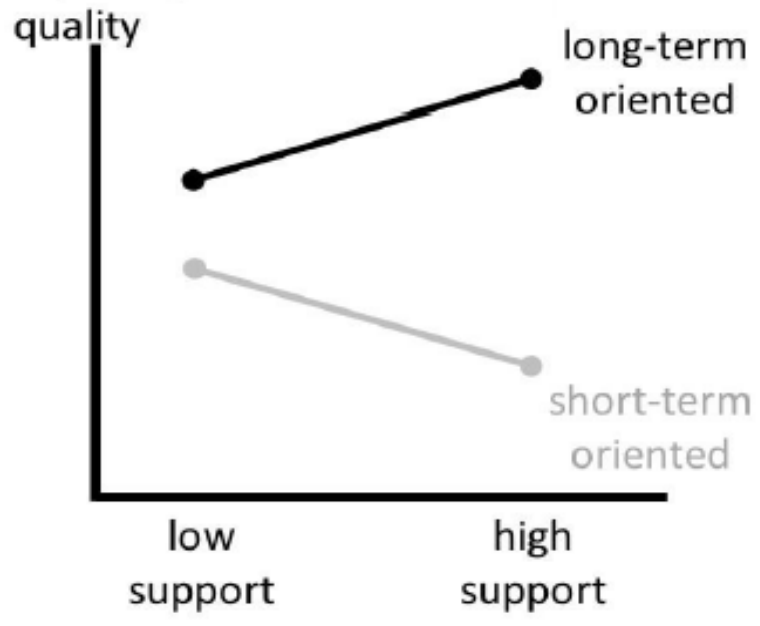

This article is protected by copyright. All rights reserved. 


\section{Data}

\section{a. Research setting: Financial intermediation}

To test our hypotheses, we conduct a field experiment in the regulatory setting of financial intermediation in the Netherlands. In general, financial intermediation regulations aim to encourage financial intermediaries to provide sound and transparent advice to potential customers of financial products, such as life insurances or mortgage loans. Because financial intermediaries tend to have more knowledge than customers about financial matters, and charge commissions or fees for the products they sell, they have incentives to provide inaccurate or unsuitable advice to customers in order to increase private gains (a practice referred to as misselling; Inderst and Ottaviani [2009]). Hence, the core objective of regulations in this, setting is to prevent misselling behavior.

To conduct the field experiment, we entered into a research collaboration agreement with the Authority for the Financial Markets (AFM), which is the supervisor of the financial markets in the Netherlands (AFM [2017]). The AFM supervises approximately 7,000 financial intermediaries, who sell or provide advice on financial products such as mortgage loans, income insurances, and damage insurances.

\section{b. Market Monitor}

As part of its supervision strategy, the AFM employs a mandatory, online selfassessment instrument called Market Monitor (MM), which gathers detailed information from all financial intermediaries on a yearly basis. This information relates to licenses and registrations, economic activities, financial products the firm specializes in, number and types of customers, number and function of employees, sales per product, and other specifics related to accounting and financial matters (Appendix A contains the translated questions used of the $2017 \mathrm{MM}$ ). The MM provides the AFM with a comprehensive overview of the accounting, financial, and managerial states of individual firms as well as the industry as a whole. At the same time, the MM helps firms to become aware of internal processes and performance, and to track their progress with regard to recommended practices.

The MM is a central element of the AFM's regulatory strategy. Although the AFM also receives customer complaints and performs random audits, completing and submitting the MM is the only or main way in which most firms interact with the AFM (unless they contact the AFM for other purposes or specific questions). Because of the size of the market, the 
AFM needs to heavily rely on signals and risk-based supervision to effectively regulate financial intermediaries. Notably, the MM is the only means through which the AFM can gather detailed information of all market participants simultaneously and on a yearly basis. The key implication is that, for most firms, interactions with the AFM are restricted to communications directly related to the MM, and in this sense, the AFM's official communications lie at the basis upon which financial intermediaries form perceptions about the AFM's regulatory strategy.

Before conducting the experiment, the AFM granted us access to the responses from the $2016 \mathrm{MM}$, which allowed us to become familiar with the data (e.g., structure, coding), design the random stratification procedure, and explore the feasibility and measurement properties of our dependent, moderator and control variables. After conducting the experiment, we were granted access to the responses from the 2017 MM. Anonymous firm identifiers allow us to track firm responses between these years. Our analysis is entirely based on anonymized MM responses

The instructions to complete and submit the MM were sent out in three batches. The number of firms included in the first, second, and third batches of 2017 are 200, 3,544, and 3,498 , respectively (these numbers differ based on the AFM's estimates about the time required by firms to complete the MM). The instruction letter was sent to all firms on Jan. 26, 2017. Subsequently, firms received a (second) letter with their username, and one day later, they received a (third) letter with the password to log into the system. The first batch received these letters on Jan. 31 and Feb. 1, the second batch on Feb. 7 and 8, and the third batch on Feb. 21 and 22. Firms in the first batch were requested to submit the completed MM between Feb. 6 and Mar. 12, firms in the second batch between Feb. 13 and Mar. 19, and firms in the last batch between Feb. 27 and Apr. 2. Upon receiving the first (instruction) letter, firms can - and are advised by the AFM to - prepare all the information requested. One week before the deadline, firms that had not completed the MM received a reminder letter. After the deadline, firms that still had not completed the MM received an additional reminder letter. A final reminder letter was sent to a small number of non-responding firms as a last opportunity to complete the MM before the AFM would take regulatory actions against the firm. Online Appendix A contains translated first and second reminder letters. 
The vast majority of firms was already familiar with the MM, and the mandatory requirement to complete it. Over 98\% of firms in our sample had completed the MM in 2016. Familiarity with the instrument is relevant for the experiment, as inexperience could confound our results (e.g., new firms receiving a letter that reflect a supportive regulatory strategy could mistakenly assume that the MM is non-mandatory).

\section{c. Experimental manipulation}

We were granted permission to manipulate the content of the three letters that the AFM uses to communicate the instructions, username, and password required to complete and submit the MM. Our objective is to introduce a manipulation that is consistent throughout these three letters, and assess its effect on reporting quality. Firms are randomly stratified to one of the following three experimental manipulations:

1. Letters that do not reflect a supportive regulatory strategy (referred to as low support letters)

2. Letters that reflect a supportive regulatory strategy, and thus signal a cooperative attitude towards the firm (high support letters)

3. Letters that are similar to the letter the authority sent out in the prior year (which the AFM requested to include). The responses of this group of firms will not be part of our analyses.

We identify three elements that a supportive regulatory strategy has, and which can be signaled via official communications. These are referred to as tone (Wenzel [2006]), purpose (Greenberg [1994]; Alford and Speed [2006]), and accessibility (Alford and Speed [2006]). As explained next, these elements are expected to affect firms' perceptions about support in the same direction.

Tone. High support letters use a supportive tone, while low support letters use a more distant, formal and authoritative tone. Wenzel [2006] showed that an authority's tone can influence agents' perceptions of interpersonal fairness (which relates to whether firms feel that they are treated with fairness and respect). As opposed to low support letters, high support letters are expected to enhance firms' perceptions of interpersonal fairness, and motivations to reciprocate the authority's cooperative attitude and comply with its requests (Smith and Stalans [1991], Smith [1992]). Hence, support in this context is expected to have a positive impact on reporting quality. 
Purpose. In the high support letters, the authority provides information about the goals of the MM, describes how these goals are aligned with the goals of the firm, and explains why it needs high quality information from the firm. In the low support letters, the authority neither provides information about the goals of the MM nor provides explicit reasons of why high quality information is valuable. These explanations are crucial, as they educate firms and allow them to "make sense" of what the AFM is requesting from them, and can therefore increase firms' cooperativeness and willingness to comply. Communicating the purpose of the MM may motivate firms to reciprocate the authority's open attitude, voluntarily share information, and engage in an open dialogue (Smith and Stalans [1991], Smith [1992]). Providing information about purpose can also enhance perceptions of procedural fairness, which relate to how firms perceive that their perspective is being taken into account (Greenberg [1994]).

Accessibility. Accessibility is one of the key elements that can enhance firms' positive experiences with the authority (Alford and Speed [2006]). We manipulate accessibility by altering the extent to which the AFM signals willingness to help firms complete the MM, but not the options that firms have to contact and receive help from the AFM. The tone and formulations of the low support letters signal that there is low willingness to help firms to complete the MM, while in the high support letters, the AFM signals a great willingness to help. We expect a signal of high (low) willingness to negatively (positively) influence firms' perceived barrier to contact the authority. A perceived low barrier to contact the authority may open a dialogue with the authority, and increase information sharing. Accessibility can also positively influence perceptions of informational and interpersonal fairness. Agents may feel they are treated with respect and provided with all information to contact the authority to successfully respond to the authority's request, which through reciprocating behavior, is motivating them to increase reporting quality (Smith and Stalans [1991]).

Appendix B contains the translated version of the letters. We conducted two pretests in different populations to assess the strength of the proposed manipulations in the instruction letter. ${ }^{2}$ First, we followed a similar approach as used in Wenzel [2006] by directly assessing group differences in perceptions based on different instruction letters that experimental participants receive. Specifically, we provided participants with similar invitation letters as to

\footnotetext{
${ }^{2}$ Details on the results of the pretests are available in Online Appendix B.
} 
be used in the field experiment, but then related to a fictional setting of tax reporting. We solicited participation of 106 bachelor students in an accounting course at a Dutch university to whom we randomly assigned the letters. After reading the letter, students filled out a set of questions about perceptions related to motivational postures towards the authority, informational and interpersonal fairness, and the authority's regulatory strategy. Results show that the high support letter was perceived as being more informationally fair, and more directed towards support than the low support letter. However, absolute differences between conditions Were relatively small. Participants' motivational postures towards the authority were not altered by the treatment. We discussed these results with the AFM and decided to strengthen the manipulation by increasing the differences between the high and low support letters (e.g., different tone and further adjusting information about goals and support).

The adjusted letters were pre-tested among 165 MSc accounting students most of whom are studying part-time and are employed in a reporting function. This test is based on a corporate tax reporting setting. Half of the students indicated to have experience in filing corporate tax returns and thus to have existing perceptions about the tax authority, which may be important to estimate the strength of the manipulation (Choo et al. [2016]). Participants were randomly assigned to one of the three instruction letters: high support, low support, or last year's letter (which we included to consult the AFM about their existing letter). After reading the letter, participants undertook a tax reporting task, and then answered a set of questions capturing motivational postures towards the authority, and perceptions of fairness, the authority, and its regulatory strategy. This allowed us to assess perceptions in response to the letter, and to have participants conduct an actual task (i.e., distraction) before gathering their perceptions. The results of this second pretest showed that the high support letter was perceived to be more informationally and interpersonally fair, and aimed at support, particularly by those students with corporate tax reporting experience. This finding may well be explained by the fact that these students have a reference framework with which they evaluate the authority's regulatory strategy. This finding also suggests that changes in communication may be effective when there were earlier interactions, which is applicable to most firms in our sample. 


\section{d. Dependent and moderating variables}

Across different regulatory settings, firms are expected to report information in a precise and complete manner (Peeters [2006], Ernst \& Young [2012]), and these aspects can be directly associated with reporting quality. Following this conceptualization, and based on the 2016 MM data (covering information from 2015) as well as on-site discussions with AFM representatives, we identified the following three elements of reporting quality: comprehensiveness, precision, and voluntary reporting.

Comprehensiveness of reporting refers to how complete firms report information to the authority. The online MM does not allow firms to skip questions (i.e., forced answering). However, intermediaries can still avoid questions by deliberately choosing responses that limit the number of follow-up questions (e.g., questions that apply to specific firm characteristics, products, and activities). ${ }^{3}$ Our measure of comprehensiveness captures the total number of questions responded to by firms. Although this does not allow us to observe whether individual firms deliberately avoided follow-up questions (e.g., by choosing options that avoid follow up questions), it does tell us whether the average number of completed questions varies between experimental conditions. Group differences would be indicative of avoiding behavior, and thus reflect differences in comprehensiveness.

Precistion of reporting refers to the precision of numerical responses, such as sales, and number of customers. For most of these questions, the AFM explicitly allows intermediaries to provide estimates instead of exact numbers.

We use nine questions in the MM to construct a measure of precision (among which are reported sales, provisions and commissions; see Table 1). We selected these questions because (i) they are relevant for the majority of firms (most firms completed these questions in the $2016 \mathrm{MM}$ ), (ii) the reported information in these questions is proprietary and requires the intermediary to gather a larger amount of information to be able to provide more precise estimates, and (iii) the responses have multiple digits. Precision of reporting is measured as follows:

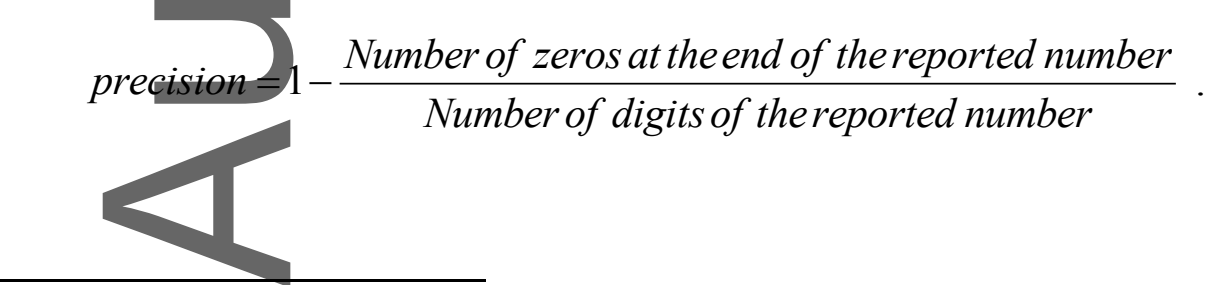

\footnotetext{
${ }^{3}$ For example, firms indicating to have part-time employees are asked to respond to follow-up questions about those employees. The same applies to specific financial products, such as mortgage loans or life insurance.
} 
In order to compare precision across treatments, we compute the average score per intermediary. For example, if the firm answered five of the nine questions, precision is equal to the average score across the five items. The possible values for this variable range from just above 0 (only the first digit is not equal to zero) to 1 (the firm did not report a zero at the end of the number). Higher scores represent more precise reporting (i.e., fewer zeros at the end of the number).

Voluntary reporting refers to whether firms respond to a non-mandatory item included in the MM, which asks intermediaries to voluntarily provide a description of the added value of their firm as compared to their competitors. Respondents can choose whether to provide this information, and if they do, they can use at maximum 250 words. Voluntary reporting is measured with a dummy variable taking the value 1 if the firm answered the question, and 0 otherwise. In a robustness test, we use the number of words provided as an alternative measure of voluntary reporting.

Overall reporting quality is a measure that combines the three different components of reporting quality indicated above. These components are expected to represent three different dimensions of reporting quality, which do not necessarily go in line. For example, firms may decide to invest time in submitting a comprehensive report, at the expense of precision or voluntary reporting. Our pre-experimental analysis of the $2016 \mathrm{MM}$ data also supported the existence of individual dimensions of reporting quality. The overall measure of reporting quality equals the sum of the standardized three components. Higher scores reflect higher reporting quality.

Time horizon is measured using two questions in which firms indicate whether they expect (1) number of employees and (2) sales to decrease, be the same, or increase in the future. The intuition behind the measure is that an expected decrease (increase) in employees and/or sales indicates organizational decline (growth) and a shorter (longer) time horizon. If a firm expects sales to grow, this indicates that future sales are relatively more important compared to current sales, and that the net present value (NPV) is relatively more dependent on future sales. Similarly, if a firm expects to hire new employees, it is likely to expect increasing business, which makes the future relatively more valuable. Hiring new employees can also be seen as an investment, which will only pay off in the future. We rate the responses to each of both questions from 1 to 3 where 1 indicates an expected decrease, 2 
expected stability, and 3 an expected increase in sales or number of employees. The correlation between the two questions is 0.301 in $2017(p<0.01)$. We use the average score of these two items as a proxy for time horizon, so that lower values represent a short-term orientation, whereas higher values represent a long-term orientation.

Firm size is captured by number of full-time employees. The 2016 data show a nonnormaldistribution, so we apply a log-transformation.

\section{Table 1. Operationalization of variables}

\begin{tabular}{|c|c|}
\hline Construct & Operationalization \\
\hline $\begin{array}{l}\text { Communicated } \\
\text { supportiveness of } \\
\text { regulatory strategy }\end{array}$ & $\begin{array}{l}\text { Experimental treatment: high support letters (1) vs. } \\
\text { low support letters (0) (see Appendix B for translated letters). }\end{array}$ \\
\hline Reporting quality & $\begin{array}{l}\text { Sum of standardized measures for comprehensiveness of reporting, } \\
\text { precision of reporting, and voluntary reporting. }\end{array}$ \\
\hline $\begin{array}{l}\text { Comprehensiveness of } \\
\text { reporting }\end{array}$ & The number of questions responded to. \\
\hline Precision of reporting & $\begin{array}{l}\text { Precision of numerical information (average of scores on items } \\
2.11,4.11,5.1,5.2,5.5,5.10,5.11,6.1 \text { and } 6.2 \text { ) measured as } 1 \\
\text { minus the number of zero digits at the end of a number divided by } \\
\text { the total number of digits in the number. }\end{array}$ \\
\hline Voluntary reporting & $\begin{array}{l}\text { Indicator whether }(1) \text { or not }(0) \text { voluntary narrative information is } \\
\text { provided to item } 1.18 \text {. }\end{array}$ \\
\hline Firm size & Natural logarithm of the number of full-time employees (item 3.2). \\
\hline Time horizon & $\begin{array}{l}\text { Average of the expected change [increase }=3 \text {, no change }=2 \text {, } \\
\text { decrease }=1 \text { ] in the number of employees (item } 3.5 \text { ), and in firm } \\
\text { sales (item 5.18). }\end{array}$ \\
\hline $\begin{array}{l}\text { Number of product } \\
\text { types }\end{array}$ & Sum of the types of products provided (item 1.4) \\
\hline Type of products & $\begin{array}{l}\text { Three indicator variables: mortgage, damage insurance, income } \\
\text { insurance (item 1.4) }\end{array}$ \\
\hline Experience & Previous experience with the Market Monitor yes/no (item 1.2) \\
\hline $\begin{array}{l}\text { Member branch- } \\
\text { organizations }\end{array}$ & Membership of a branch organization yes/no (item 1.13) \\
\hline Franchise & Franchisee of a franchise organization yes/no (item 1.11) \\
\hline Batch & $\begin{array}{l}\text { Indicator variable for the batch the firm was in ( } 2 \text { dummy } \\
\text { variables: group } 1 \text { or } 2 \text { ) }\end{array}$ \\
\hline
\end{tabular}

Note: Item numbers refer to questions in the 2017 Market Monitor (see Appendix A). All data used for variable measurement are derived from the Market Monitor.

This article is protected by copyright. All rights reserved. 


\section{e. Control variables}

We control for (1) the number of different product types that intermediaries sell as well as specific types of products, (2) prior experience with the MM (as indicated by having completed the previous MM), (3) connections to branch organizations, (4) franchise connections, and (5) the batch in which the letters were sent out.

Intermediaries can sell 13 different types of products for which they need a license issued by the AFM. As a greater product range makes more questions in the MM applicable, we control for the number of product types that intermediaries sell. The maximum value of this variable is 13. We also include dummy variables to control for whether firms sell any of the three most frequently sold product types: damage insurance, mortgages, and income insurance, as these may receive relatively more attention in the $\mathrm{MM} .{ }^{4}$ We further control for the potential effect of having prior experience with the MM, as prior interactions with the AFM and this instrument can affect how firms respond to the manipulation. Prior experience can make firms better prepared to respond to an information request, and influence attitudes towards the authority. On the other hand, our pre-tests signaled that experience can make the treatment effect stronger, as the firm has a reference to compare the treatment to. We further control for whether the firm is a member of one or more branch organizations, as interactions with these connections may also affect intermediaries' perceptions. Similarly, we control for whether the firm is part of a franchise, which may affect the firm's information environment and connections. Finally, we include two dummy variables to control for the batch number the firm was part of, as the MM is sent out in different batches.

Table 1 provides an overview of the constructs and their operationalization.

\section{f. Random assignment}

In order to test our hypotheses, we used a stratified random sampling approach to assign the treatment to firms. Using the $2016 \mathrm{MM}$ data, we first derived the score for each firm on the time horizon measure. This yields five different time horizon groups (the average score for items 3.5 and 5.18 can take any of the following values: 1, 1.5, 2, 2.5, and 3). Within these groups we ordered firms by size, and then randomly assigned the treatments to the

\footnotetext{
${ }^{4}$ Other products for which intermediaries need an AFM license are: consumer credit, electronic money, capital products, health insurance policies, pension insurance policies, premium pension claims, participation rights in investment companies, investment objects, payment accounts, and savings accounts.
} 
firms. In this way we assured that within each time horizon level, treatments are randomly assigned to intermediaries with different sizes. Figure 2 depicts the random stratification procedure. In each of the treatment conditions, there are approximately 2,400 intermediaries. To test our hypotheses, we only focus on the high- and low-support group.

\section{Figure 2. Random stratification of intermediaries}

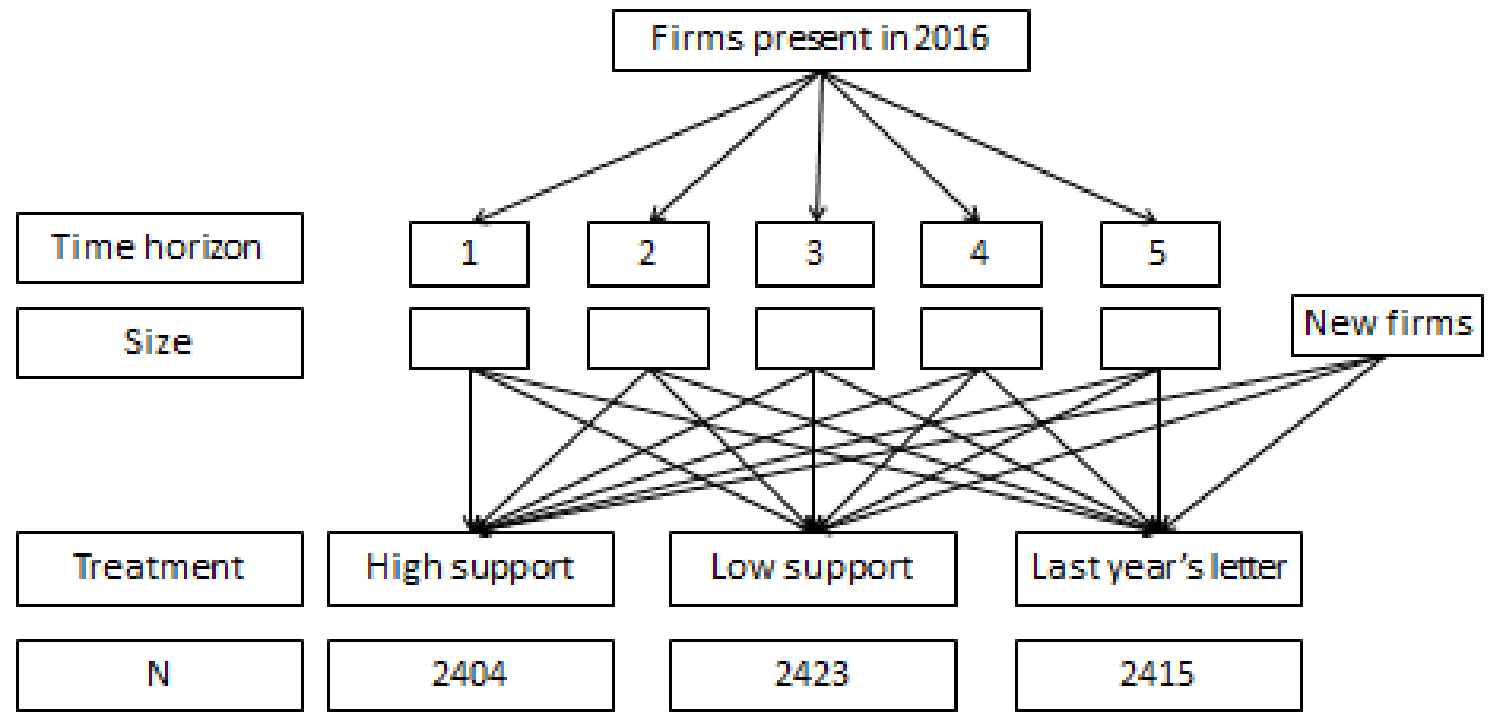

We also used the $2016 \mathrm{MM}$ data to examine if the two stratification conditions (firm size and time horizon) as well as existing perceptions about the authorities' information provision concerning the MM are associated with the treatment conditions. Associations between these variables and the treatment could affect the results of the experiment. Existing perceptions on the authorities' information provision concerning the MM are captured by the responses to two statements in the MM, being the extent to which respondents believed that (1) they were timely informed about the MM, and (2) it was clear to them which information they needed to collect to complete it. We find no significant differences between the treatment groups for firm size ( $t$-stat. -0.3958$)$, time horizon (t-stat. 0.0427), and these perceptions ( $t$-stat. 0.6814 and 0.4403 ). This provides confidence that our random stratification procedure was successful.

\section{Research design}

Summary statistics are reported in Table 2. The samples sizes for the 2016 and $2017 \mathrm{MM}$ are 4,323 and 4,577, respectively. Reporting quality is the sum of the standardized values of 
comprehensiveness of reporting, precision of reporting, and voluntary reporting. In the 2017 MM (which refers to data over 2016), firms on average responded to 54\% of the 111 questions included, reported with an average precision of $70 \%$, and had a voluntary reporting response of $41 \%$.

Table 2. Summary statistics ${ }^{5}$

\begin{tabular}{|c|c|c|c|c|c|c|}
\hline Variable & $\begin{array}{l}\text { MM } \\
\text { year }\end{array}$ & Mean & SD & Q1 & Median & Q3 \\
\hline \multirow{3}{*}{$\begin{array}{l}\text { Reporting quality } \\
\text { Comprehensiveness of reporting }\end{array}$} & 2017 & 0.000 & 1.740 & -1.188 & -0.052 & 1.157 \\
\hline & 2016 & 0.056 & 1.701 & -1.191 & 0.012 & 1.251 \\
\hline & 2017 & 59.674 & 7.767 & 55.000 & 60.000 & 65.000 \\
\hline \multirow{3}{*}{ Precision of reporting } & 2016 & 60.338 & 7.681 & 55.000 & 61.000 & 65.000 \\
\hline & 2017 & 0.692 & 0.142 & 0.590 & 0.682 & 0.790 \\
\hline & 2016 & 0.686 & 0.143 & 0.583 & 0.677 & 0.781 \\
\hline \multirow{2}{*}{ Voluntary reporting } & 2017 & 0.407 & 0.491 & 0.000 & 0.000 & 1.000 \\
\hline & 2016 & 0.413 & 0.492 & 0.000 & 0.000 & 1.000 \\
\hline \multirow[t]{2}{*}{ Firm size } & 2017 & 1.073 & 0.778 & 0.693 & 0.693 & 1.386 \\
\hline & 2016 & 1.072 & 0.785 & 0.693 & 0.693 & 1.386 \\
\hline \multirow[t]{2}{*}{ Time horizon } & 2017 & 2.174 & 0.462 & 2.000 & 2.000 & 2.500 \\
\hline & 2016 & 2.183 & 0.473 & 2.000 & 2.000 & 2.500 \\
\hline \multirow[t]{2}{*}{ Mortgage } & 2017 & 0.645 & 0.479 & 0.000 & 1.000 & 1.000 \\
\hline & 2016 & 0.636 & 0.481 & 0.000 & 1.000 & 1.000 \\
\hline \multirow[t]{2}{*}{ Damage insurance } & 2017 & 0.869 & 0.338 & 1.000 & 1.000 & 1.000 \\
\hline & 2016 & 0.883 & 0.322 & 1.000 & 1.000 & 1.000 \\
\hline \multirow[t]{2}{*}{ Income insurance } & 2017 & 0.758 & 0.429 & 1.000 & 1.000 & 1.000 \\
\hline & 2016 & 0.773 & 0.419 & 1.000 & 1.000 & 1.000 \\
\hline \multirow[t]{2}{*}{ Number of products } & 2017 & 5.127 & 2.730 & 3.000 & 5.000 & 7.000 \\
\hline & 2016 & 5.451 & 2.615 & 3.000 & 5.000 & 7.000 \\
\hline \multirow[t]{2}{*}{ Experience } & 2017 & 0.984 & 0.127 & 1.000 & 1.000 & 1.000 \\
\hline & 2016 & 0.986 & 0.118 & 1.000 & 1.000 & 1.000 \\
\hline \multirow[t]{4}{*}{ Branch organization } & 2017 & 0.605 & 0.489 & 0.000 & 1.000 & 1.000 \\
\hline & 2016 & 0.603 & 0.489 & 0.000 & 1.000 & 1.000 \\
\hline & 2017 & 0.095 & 0.293 & 0.000 & 0.000 & 0.000 \\
\hline & 2016 & 0.089 & 0.285 & 0.000 & 0.000 & 0.000 \\
\hline \multicolumn{7}{|l|}{2017 MM procedure } \\
\hline Batch 1 & & 0.030 & 0.171 & 0.000 & 0.000 & 0.000 \\
\hline Batch 2 & & 0.488 & 0.500 & 0.000 & 0.000 & 1.000 \\
\hline Batch 3 & & 0.482 & 0.500 & 0.000 & 0.000 & 1.000 \\
\hline Reminder letter 1 & & 0.642 & 0.479 & 0.000 & 1.000 & 1.000 \\
\hline Reminder letter 2 & & 0.081 & 0.272 & 0.000 & 0.000 & 0.000 \\
\hline Last reminder letter & & 0.005 & 0.068 & 0.000 & 0.000 & 0.000 \\
\hline
\end{tabular}

\footnotetext{
${ }^{5}$ In the proposal, we indicated to report maximum and minimum values in Table 2. However, because of confidentiality reasons, we have been asked to report Q1, median, and Q3 instead.
}

This article is protected by copyright. All rights reserved. 
Note: For MM 2016, $N=4,323$, and for MM 2017, $N=4,577$. The first reminder letter was sent out to firms that had not completed the MM one week before the deadline, the second and final reminder letters were sent after the deadline. Online Appendix A contains translated first and second reminder letters. Variable definitions are provided in Table 1.

Firms in the industry are relatively small, ranging in the majority of cases between 0 and 10 full time employees (note firm size statistics reported in Table 2 are log-transformed). Firms are relatively more long-term oriented than short-term oriented, as time horizon on average lies above the midpoint of the scale $(2.2>2)$. Firms sell on average five types of products. Damage insurance, income insurance, and mortgage loans are sold by $87 \%, 76 \%$, and $64 \%$ of firms, respectively. Most firms have experience with the MM, as in 2017 less than $2 \%$ completed it for the first time. In the industry, $60 \%$ of firms are connected to a branch organization, and $9 \%$ are part of a franchise chain.

The AFM sent out instruction letters in three batches. The first batch contained approximately $3 \%$ of the sample. The second and third batches are similar in size $(49 \%$ and $48 \%$, respectively). A first reminder letter was sent out to $64 \%$ of firms before the deadline, and a second reminder letter to $8 \%$ of firms after the deadline. A 'last reminder letter' was sent out to $0.5 \%$ of firms, with a final request to complete the MM before taking regulatory actions. The experimental treatment is not significantly correlated with being part of these batches or receiving any of the reminder letters (as these are dummy variables, we estimate tetrachoric correlation coefficients, and in all cases $p>0.10$ ).

Table 3 contains Pearson correlations between the main variables of interest. Receiving a high support letter is negatively though not significantly correlated with reporting quality ( $r=$ $-0.02 ; p=0.14$ ) nor with any of its components. Reporting quality is, however, positively correlated with firm size $(r=0.30 ; p<0.01)$ and time horizon $(r=0.20 ; p<0.01)$. This indicates that firm characteristics influence reporting quality. Relatively larger firms report in a more comprehensive $(r=0.48 ; p<0.01)$ and precise $(r=0.05 ; p<0.01)$ manner, but do not differ from smaller firms in terms of voluntary reporting $(r=0.01 ; p>0.10)$. For long-term oriented firms, reporting is more comprehensive, precise, and voluntary (in these three cases, $p<0.01)$. Moreover, the positive association between firm size and time horizon $(r=0.20 ; p$ $<0.01$ ) indicates that larger firms tend to be more long-term oriented.

Table 3. Pearson correlations

This article is protected by copyright. All rights reserved. 


\begin{tabular}{|c|c|c|c|c|c|c|c|}
\hline & & $(1)$ & (2) & (3) & $(4)$ & $(5)$ & $(6)$ \\
\hline 1 & High support letter $^{6}$ & 1.000 & & & & & \\
\hline 2 & Reporting quality & -0.022 & 1.000 & & & & \\
\hline 3 & Comprehensiveness & -0.007 & $0.578^{* * *}$ & 1.00 & & & \\
\hline 4 & Precision & -0.017 & $0.598^{* * *}$ & $0.032^{* *}$ & 1.000 & & \\
\hline 5 & Voluntary reporting & -0.014 & $0.565^{* * *}$ & $-0.027^{*}$ & 0.009 & 1.000 & \\
\hline 6 & Firm size & 0.002 & $0.304^{* * *}$ & $0.477^{* * *}$ & $0.047^{* * *}$ & 0.005 & 1.000 \\
\hline 7 & Time horizon & -0.012 & $0.198^{* * *}$ & $0.261^{* * *}$ & $0.029^{*}$ & $0.054^{* * *}$ & $0.205^{* * *}$ \\
\hline
\end{tabular}

\section{a. Statistical testing}

Hypothesis 1 focuses on the main effect of the high support letter on reporting quality, whereas Hypotheses 2 and 3 focus on how this effect is moderated by firm size and time horizon. For each hypothesis, we employ not only reporting quality as predicted variable, but also each of its three components. To test Hypothesis 1, we assess group differences (between treatments) using $t$-tests and $\chi^{2}$-tests, as well as OLS and logit regressions in which we control for the potential influence of relevant variables. The baseline model is specified as follows:

(1) Reporting quality $=\alpha+\beta_{1} \cdot$ high support letter $+\beta_{2} \cdot$ time horizon $+\beta_{3} \cdot$ firm size + $\sum_{i=4.12} \beta_{i}$ control variable $_{i}+\varepsilon$

Our expectation is that $\beta_{1}$ is positive and significant.

Hypotheses 2 and 3 are tested simultaneously, using an extended version of the baseline model that incorporates interaction terms. To test Hypothesis 2, we include the interaction between firm size and the treatment variable, which we expect to be negative and significant. Hypothesis 3 predicts that the effect of the high support letter on reporting quality is (i) positive when time horizon is high (i.e., when firms are long-term oriented), and (ii) negative when time horizon is low (i.e., when firms are short-term oriented). Hypothesis 3 is tested in two ways. First, we replace the time horizon variable with two dummies: one for short-term oriented firms (taking the value 1 if the time horizon score lies below the midpoint of the scale, and 0 otherwise), and another dummy for long-term oriented firms (taking the value 1 if the score lies above the midpoint of the scale, and 0 otherwise). The regression model includes both dummies and their corresponding interactions with the treatment variable. In this way, we can assess the expected positive and negative interaction effects (for long-term

\footnotetext{
${ }^{6}$ This table slightly deviates from the proposal as the 'High support letter' variable was not included.
} 
and short-term oriented firms, respectively) in the same regression. Under this model specification, the regression intercept captures the time horizon scores that lie at the midpoint of the seale (i.e., medium-term oriented firms are treated as the reference category).

Second, we test Hypothesis 3 by generating a categorical time-horizon variable that has three levels - for short, medium, and long-term oriented firms (taking the values 1, 2, and 3 if the score is less than, equal to, and greater than the midpoint of the time horizon scale). We run a regression in which we incorporate the interaction between the treatment and this categorical variable, and use this interaction to estimate and compare the marginal effects of the three time horizon categories across the two experimental conditions. ${ }^{7}$ As we expect an antagonizing interaction effect (which is negative for the first level, and positive for the third level), we do not formulate an empirical expectation about the sign or the significance of the interaction term. For both regressions (one using two time horizon dummies, and another using one categorical time horizon variable), we assess whether the effect of the high support letter is larger for long-term oriented firms, and smaller for short-term oriented firms, as compared to other possible combinations between treatments and time horizon levels.

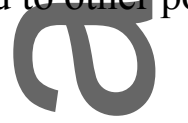

\section{Results}

\section{a. Hypothesis 1}

To assess the treatment effect as predicted in Hypothesis 1, we first estimate mean and frequency differences between experimental conditions as registered in the proposal. In line with the correlation coefficients presented in Table 3, the reported $t$ and $\chi^{2}$ tests in Tables 4 and 5 indicate that there are no differences between experimental conditions in reporting quality or any of its components.

We also assess the significance of the treatment effect by conducting a planned regression analysis in which we control for relevant covariates. We employ linear regressions for reporting quality, comprehensiveness, and precision of reporting, and a logit regression for voluntary reporting. The results are presented in Table 6 , and indicate that the treatment has no main effect on the predicted variables.

\section{Table 4. Meandifferences and $t$-tests for reporting quality and two of its components} (planned tests)

\footnotetext{
${ }^{7}$ In the planned additional tests we also run this analysis refining the time horizon measure to all five possible values, which was conditional on obtaining enough observations per level.
}

This article is protected by copyright. All rights reserved. 


\begin{tabular}{l|rr|r}
\hline & High support & Low support & Difference \\
\hline Reporting quality & -0.038 & 0.038 & $0.076(0.140)$ \\
Comprehensiveness of reporting & 59.619 & 59.730 & $0.111(0.629)$ \\
Precision of reporting & 0.690 & 0.695 & $0.005(0.243)$ \\
\hline
\end{tabular}

$p$-values are in parentheses.

Table 5. Contingency table for frequencies of voluntary reporting (planned test)

\begin{tabular}{l|rr|r}
\hline & High support & Low support & Total \\
\hline Voluntary reporting $=1$ & 917 & 946 & 1,863 \\
Voluntary reporting $=0$ & 1,374 & 1,341 & 2,715 \\
& & & \\
\hline Total & 2,291 & 2,287 & 4,578 \\
$\chi^{2}$ & & & $0.849(0.357)$ \\
\hline
\end{tabular}

$p$-value is in parentheses.

We run four regressions simultaneously, which can affect the likelihood of finding significant results in one or more of them. As planned, we follow theorem 3.1 of List, Shaikh, and $\mathrm{Xu}[2016]$ to correct the $p$-values of the independent variable for family-wise error rates (e.g., inflated alphas), and obtain the same pattern of results (untabulated; corrected $p$-values of the treatment effect are 0.476 for comprehensiveness, 0.454 for precision, and 0.576 for voluntary reporting).

Table 6 also indicates that reporting quality is negatively associated with having experience with the MM, and positively associated with firm size, time horizon, being connected to a branch organization, selling of mortgage loans or income insurance, and the number of products sold. The negative effect of experience indicates that reporting quality is higher for the small fraction of new firms that completed the MM for the first time in 2017. New firms may have particularly strong motivations to act responsibly and comply with the authority's requests. The effects of firm size and number of products sold can be expected, as they relate primarily to comprehensiveness of reporting, and may in part derive from the fact that these firms have more information to report. The positive effect of connections to branch organizations goes in line with the idea that firm behavior is influenced not only by the authority, but also by peers and industry actors. Time horizon relates positively and significantly to both comprehensiveness of reporting and voluntary reporting. The effects of the other control variables on the subcomponents of reporting quality are ambiguous, as the coefficients vary in signs and significance.

Table 6. Regression results Hypothesis 1 (planned tests)

This article is protected by copyright. All rights reserved. 


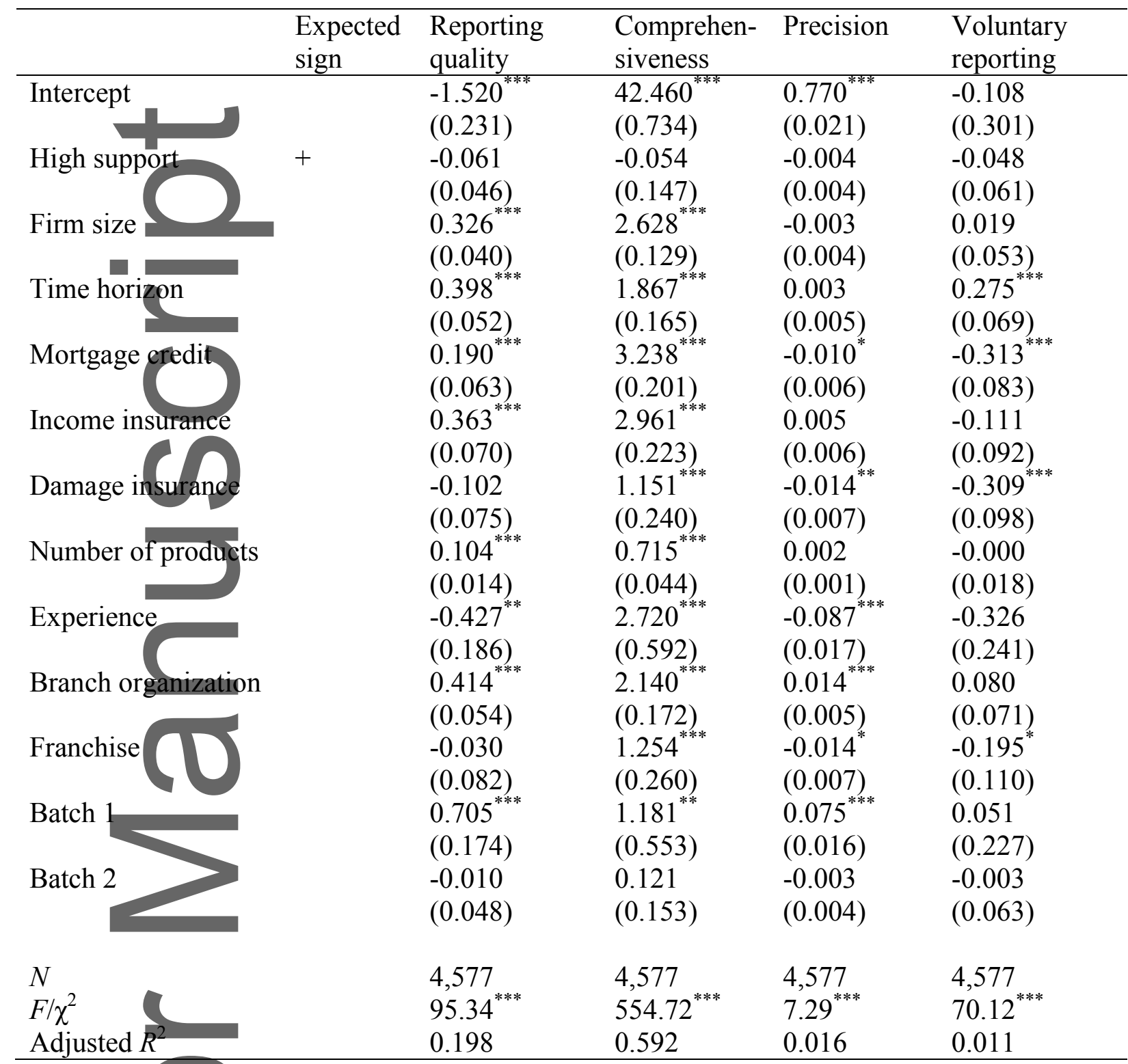

Standard errors are in parentheses. ${ }^{* * *},{ }^{* *}$, and $*$ indicate significance at the $0.01,0.05$, and 0.10 level (twotailed), respectively.

\section{b. Hypotheses 2 and 3}

In order to test whether the effect of the high support letter on reporting quality is weakened by firm size (Hypothesis 2), and strengthened and reversed by long and short-term orientation, respectively (Hypothesis 3), we incorporate interaction terms in the regression model presented in Table 6. Table 7 presents the results of these planned tests. The control variables are included in all regressions but not reported, as they follow the same pattern of results as in Table 6 .

The results do not support Hypothesis 2. None of the four dependent variables is associated with the interaction between high support and firm size (all $p$-values $>0.10$ ). 
Reporting quality increases as firms become larger, independent of the level of support in the letters that they receive $(\beta=0.360 ; p<0.01)$, and this effect is primarily driven by increases in comprehensiveness $(\beta=2.772, p<0.01)$.

The main effects also show that long-term oriented firms report higher quality data to the $\operatorname{AFM}(\beta=0.279 ; p<0.01)$ than short and medium-term oriented firms. However, short-term oriented firms do not deliver significantly lower quality data than medium-term oriented firms $(\beta=0.116 ; p>0.10)$. The interactions with the time horizon indicators provide partial support for Hypothesis 3. Short-term orientation does not significantly moderate the effect of the high support letter on reporting quality, but long-term orientation does $(\beta=0.201, p<$ 0.05). This overall effect is not due to the individual components of reporting quality, but relates to the combination of components. Although not significant, the sign of the interaction term between high support and long-term orientation is positive across the three reporting quality components. The significant interaction effect needs to be analyzed in concert with the negative main effect of high support $(\beta=-0.151, p<0.05)$. A plausible interpretation is that the high support letter sends a signal of a soft or weak enforcement strategy, under which the detection and punishment of non-compliance appear to be less of a priority for the authority. Considering that reporting quality is costly for firms (in terms of, e.g., effort, time, specialized personnel), high support may have the unintended effect of demotivating firms to attain highreporting quality. The negative effect of high support is, however, counteracted by a long-term orientation. For long-term oriented firms, a high support letter is less likely to negatively affect reporting quality. This goes in line with the idea that long-term oriented firms see reporting quality as a continuous investment, which has longer term internal benefits (e.g., to track changes, identify weaknesses through time), and external benefits for the relationship with the authority (e.g., to build trust, fluent communication, and a reliable mutual learning process). In this sense, a long-term orientation may act as a buffer against possible changes in the perceived strength of the authority's enforcement strategy.

Table 7. Regression results Hypotheses 2 and 3 (planned tests)

\begin{tabular}{llllll}
\hline & $\begin{array}{c}\text { Exp. } \\
\text { sign }\end{array}$ & $\begin{array}{l}\text { Reporting } \\
\text { quality }\end{array}$ & $\begin{array}{l}\text { Comprehen- } \\
\text { siveness }\end{array}$ & Precision & $\begin{array}{l}\text { Voluntary } \\
\text { reporting }\end{array}$ \\
\hline Intercept & & $-0.804^{* * * *}$ & $45.824^{* * *}$ & $0.777^{* * *}$ & 0.387 \\
& & $(0.198)$ & $(-0.633)$ & $(0.018)$ & $(0.258)$ \\
High support (HS) & $-0.151^{* *}$ & -0.067 & -0.009 & $-0.168^{*}$ \\
& & $(0.072)$ & $(0.230)$ & $(0.007)$ & $(0.096)$ \\
\hline
\end{tabular}




\begin{tabular}{|c|c|c|c|c|c|}
\hline Firm size (FS) & & $\begin{array}{l}0.360^{\text {**** }} \\
(0.050)\end{array}$ & $\begin{array}{l}2.772^{* * *} \\
(0.158)\end{array}$ & $\begin{array}{l}-0.005 \\
(0.004)\end{array}$ & $\begin{array}{l}0.078 \\
(0.065)\end{array}$ \\
\hline Short-term orientation (STO) & & $\begin{array}{l}-0.116 \\
(0.097)\end{array}$ & $\begin{array}{l}-0.527^{*} \\
(0.310)\end{array}$ & $\begin{array}{l}0.000 \\
(0.009)\end{array}$ & $\begin{array}{l}-0.093 \\
(0.129)\end{array}$ \\
\hline Long-term orientation (LTO) & & $\begin{array}{l}0.279^{* * *} \\
(0.072)\end{array}$ & $\begin{array}{l}1.508^{* * *} \\
(0.231)\end{array}$ & $\begin{array}{l}0.000 \\
(0.007)\end{array}$ & $\begin{array}{l}0.179^{*} \\
(0.095)\end{array}$ \\
\hline HS x FS & - & $\begin{array}{l}-0.050 \\
(0.060)\end{array}$ & $\begin{array}{l}-0.171 \\
(0.191)\end{array}$ & $\begin{array}{l}0.004 \\
(0.005)\end{array}$ & $\begin{array}{l}-0.108 \\
(0.079)\end{array}$ \\
\hline HS x STO & - & $\begin{array}{l}0.058 \\
(0.136)\end{array}$ & $\begin{array}{l}0.087 \\
(0.435)\end{array}$ & $\begin{array}{l}-0.005 \\
(0.012)\end{array}$ & $\begin{array}{l}0.180 \\
(0.181)\end{array}$ \\
\hline HS x LTC & + & $\begin{array}{l}0.201^{* *} \\
(0.101)\end{array}$ & $\begin{array}{l}0.045 \\
(0.323)\end{array}$ & $\begin{array}{l}0.013 \\
(0.009)\end{array}$ & $\begin{array}{l}0.219 \\
(0.134)\end{array}$ \\
\hline $\begin{array}{l}N \\
F / \chi^{2} \\
\text { Adjusted } F\end{array}$ & & $\begin{array}{l}4,577 \\
72.83^{\text {*** }} \\
0.201\end{array}$ & $\begin{array}{l}4,577 \\
415.11^{* * *} \\
0.591\end{array}$ & $\begin{array}{l}4,577 \\
5.85^{* * *} \\
0.017\end{array}$ & $\begin{array}{l}4,577 \\
79.53^{\text {*** }} \\
0.013\end{array}$ \\
\hline
\end{tabular}

Note: Exp. stands for "Expected". The control variables are the same as in Table 6, but are not reported in this table for brevity. Standard errors are in parentheses. ${ }^{* *},{ }^{* *}$, and $*$ indicate significance at the $0.01,0.05$, and 0.10 level (two-tailed), respectively. The exact $p$-values of HS x LTH on comprehensiveness, precision, and voluntary reporting are $0.889,0.160$, and 0.101 .

\section{c. Marginal effects}

Theregression results presented in Table 7 are used to estimate the marginal effects of high support on reporting quality for short- and long-term oriented firms. In line with our proposal, the differences between marginal effects are reported in Table 8 . The estimations show that reporting quality significantly decreases with short-term orientation, and significantly increases with long-term orientation. The key finding is that the high support letter leads to lower reporting quality when firms are not long-term oriented (i.e., for LTO = 0 , high support reduces reporting quality by $0.118, p=0.052)$, while for long-term oriented firms reporting quality is similar across the two letters. As explained earlier, long-term orientation may prevent firms from taking advantage of what may be perceived as a softer or weaker enforcement strategy.

Table $8{ }^{8}$ Marginal effects of high support on reporting quality for short and long-term orientation (planned tests)

\begin{tabular}{lrrr|rrr}
\hline & \multicolumn{3}{c|}{ Short-term orientation (STO) } & \multicolumn{3}{c}{ Long-term orientation (LTO) } \\
& STO =0 & STO = 1 & Difference & LTO =0 & LTO = 1 & Difference \\
\hline High support =0 & 0.141 & -0.504 & $-0.645^{* * *}$ & -0.217 & 0.357 & $0.574^{* * *}$ \\
High support = 1 & 0.064 & -0.581 & $-0.645^{* * *}$ & -0.336 & 0.379 & $0.715^{* * *}$ \\
\hline
\end{tabular}

\footnotetext{
${ }^{8}$ This table reports the results differently than how we proposed it. The current table is more functional and provides more insight into the interaction between the treatment and time horizon.
}

This article is protected by copyright. All rights reserved. 
Note: STO = $1(0)$ refers to the group of firms that are have scores below (equal to or above) the midpoint of the time horizon measure. Similarly, LTO $=1(0)$ refers to the group of firms that have scores above (equal to or below) the midpoint of the time horizon measure.

\section{d. Unexpected events during the study and their effects on the results}

As part of the two-stage editorial process, authors commit to the methodology and research design before the study is conducted and the data are collected. Especially in the case of a field experiment, this process provides scope for unexpected events to influence the data gathering process (and possibly also results). We encountered three events that were beyond our control but require attention.

First, dhe to an error in the letter printing process outsourced by the AFM, around 30 firms received the invitation letter on printing paper of another company (Heineken) instead of AFM paper. The AFM contacted each of these firms as soon as they noticed the mistake. The error reeeived limited media attention which likely has reached at least part of the firms in the sample. If we exclude the firms that received the flawed letter from the analysis, we find similar results, with the exception that the positive effect of the interaction between the high support letter and long-term orientation on voluntary reporting becomes marginally significant $(p<0.10)$.

Second, another printing error caused the second batch of firms to receive the username letter twice instead of first the username letter and then the password letter. The AFM corrected this mistake by sending an additional letter with the password. By controlling for batches in the main analysis, we already take the potential effect of this error into account.

Third, the AFM sent three different reminder letters during the process: the first a week before the deadline, the second after the deadline, and then a third final reminder letter (see section $3 \mathrm{~b}$ for a more thorough explanation). Approximately $13 \%$ of intermediaries did not meet the deadline, which was a greater proportion than expected based on prior experience. The majority of these late respondents received multiple (generic) reminder letters, which may have diluted the treatment effect, and these firms may also have different motivations than those responding in time. We conduct two tests to assess the potential impact of this proportion of late responses. First, we use dummy variables to indicate if a firm received a particular reminder letter and include them as additional covariates in the main analysis. This yields the same pattern of results and strengthens the association between reporting quality and the interaction between high support and long-term orientation $(p<0.05)$. Second, we 
redo all main analyses excluding late respondents. Results are similar to those reported above, except for a marginally significant negative difference in average reporting quality between experimental groups $(p<0.10)$.

\section{Additional analyses}

A. Change in reporting quality. As proposed, we conduct an additional analysis to examine whether the experimental treatment is associated with the change in reporting quality and its three components (where change $=2016$ score -2015 score). For comprehensiveness, the score is scaled using the total number of questions from the corresponding year (i.e., change $=2016$ score $/ 111$ items -2015 score $/ 109$ items). The results of the $t$ and $\chi^{2}$ tests, as well as the regression analysis do not provide evidence in favor of a treatment effect on any of these change variables. When we include the interaction terms, however, we find a reasonably similar pattern of results as in Table 7. The main effect of high support is negative though no longer significant $(p=0.16)$, and the same holds for the positive interaction between high support and long-term orientation $(p=0.11)$. The main effect of firm size is positive for the change in reporting quality $(p<0.01)$, comprehensiveness $(p<0.01)$, and voluntary reporting $(p<0.05)$; and the main effect of long-term orientation is positive for the change in reporting quality $(p<0.05)$ and comprehensiveness of reporting $(p<0.01)$. In line with Hypothesis 2 , the effect of the interaction between firm size and high support is negative for the change in voluntary reporting $(p<0.01)$. In line with Hypothesis 3 , the effect of the interaction between long-term orientation and high support is positive for the change in precision of reporting $(p<0.05)$. Online Appendix $\mathrm{C}$ reports the tabulated results.

B. Perceptions of informational fairness. We use the average score of responses on the following two statements (item 8.1 in the MM) to create a measure of informational fairness: "I was informed about the Market Monitor in a timely manner", and "It was sufficiently clear which information my organization had to gather in order to provide answers to the questions in the Market Monitor" (Cronbach $\alpha=0.90$ ). These items are indicative of perceived informational fairness as they relate to being informed in a sufficient and timely manner. Responses were provided on a five-point scale, ranging from "completely disagree" to "completely agree". The results of the planned additional $t$-tests indicate that informational fairness does not differ across experimental conditions. These results are not in line with 
those of the pre-tests, namely that the treatment significantly influenced perceptions of informational fairness, especially for participants with reporting experience. Furthermore, correlations between perceptions of informational fairness and the measures of reporting quality are close to zero and non-significant. OLS and logit regressions confirm that perceptions of informational fairness are not significantly related to reporting quality.

C. Benford's Law. Benford's law describes the phenomenon that the first four digits of randomly reported numbers follow specific frequency distributions (Benford [1938], Hill [1995]). Frequency distributions that deviate from Benford's law may indicate that reported numbers are fraudulent or imprecise (examples of applications of Benford's law are in Carslaw [1998], Durtschi, Hilison, and Pacini [2004], Nigrini [1996]). For example, if reporters round numbers, this will cause increases in the frequency of zeros relative to the base prediction of Benford's law.

In a planned additional analysis, we use $\chi^{2}$ tests to estimate differences in precision between experimental groups, by comparing their frequency distributions of digits for reported sales (MM item 6.1) with Benford's frequency distribution. Hypothesis 1 predicts that the low support group will report with lower precision than the high support group. Accordingly, we expect that the low support group will show larger deviations from Benford's distribution than the high support group, and that deviations occur at an earlier digit (e.g., at the second instead of third digit). Figure 3 shows for the first four digits the frequency distributions for both the high and low support group relative to Benford's law.

\section{Figure 3. Tests of deviations from Benford's law (planned additional analysis)}

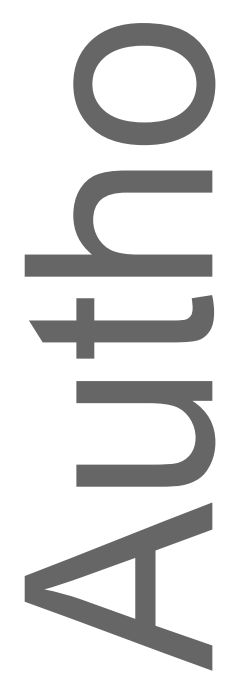




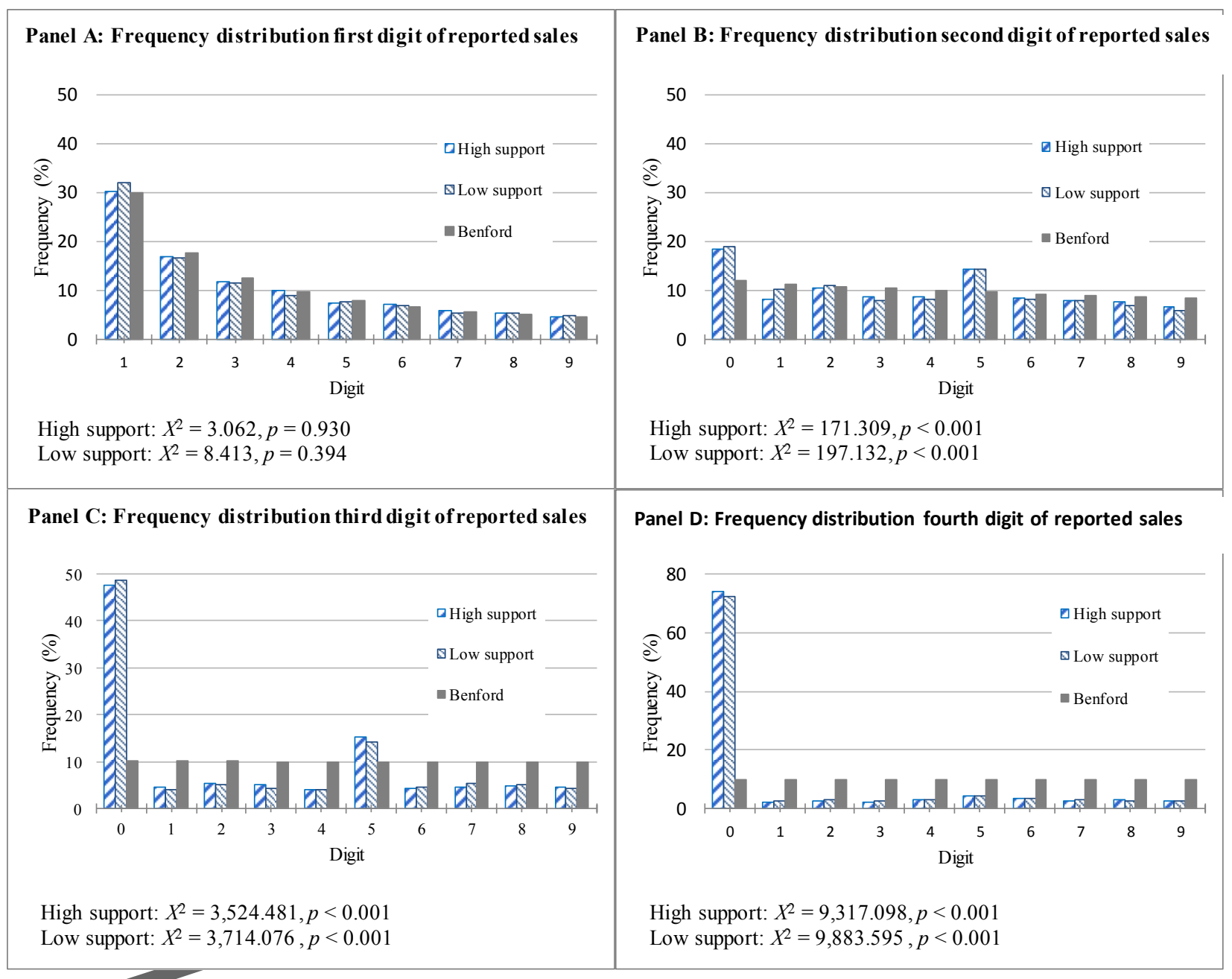

Figure 3 shows for the first, second, third, and fourth digit of reported sales, how frequent firms reported a particular number. Reported $X^{2}$ ( $p$-values) refer to the test statistic (significance) of differences in frequency distributions between the treatment group and Benford's law.

In both experimental conditions, the first digit (Panel A) does not significantly deviate from Benford's aw, while the distribution of the second digit (Panel B) shows a more frequent observation of zeros and fives than predicted, indicating that firms round numbers. For each of the treatment conditions, the differences with Benford's frequency distribution are highly significant $(p<0.001)$. We find similar results for the frequency distributions of the third and fourth digit (Panel C and D); observed zeros in both experimental conditions are much more frequent than Benford's frequency distributions would predict. These results are consistent with common use of rounding by intermediaries at these digits, but reveal no differences between the experimental groups. Indeed, tests of differences between experimental groups in the frequencies of reported zeros and fives show no significant differences for all four digits (all $p$-values $>0.05$ ).

This article is protected by copyright. All rights reserved. 
D. Timeliness in responding. The AFM requires intermediaries to report the requested information within a particular timeframe as effective supervision requires timely reporting of information. Therefore, in this planned additional test, we examine how our treatment influences timeliness in reporting, using a dummy variable that indicates whether intermediaries submitted responses in time (0) or not (1). ${ }^{9}$

In the high and low support conditions, $13.92 \%$ and $12.29 \%$ of the firms submitted after the deadline, respectively. This difference is not significant ( $p$-value of $X^{2}$ test $\left.=0.101\right)$. A planned logistic regression analysis (Table 9, column 1) further shows that the interaction effect between the treatment and long-term orientation is positive and significant $(\beta=0.476$, $p<0.01$ ). This indicates that long-term oriented firms receiving a high support letter were less likely to meet the deadline. If long-term orientation captures motivations to act responsibly, a low support letter (which makes the deadline more salient) may move longterm oriented firms to report in time.

E. Alternative measure of time horizon. Our proposal (footnote 4) includes a planned test that was conditional on the time horizon variable having sufficient observations for the minimum (1) and maximum (3) values. As each time horizon category has sufficient observations, we conduct the planned analysis and contrast the extremes with the levels in the middle $(1.5,2$ and 2.5$)$. The results are depicted in Figure 4, and show that the effect of the high support letter is negative for the shortest time horizon $($ th $=1)$, leading to lowest level of reporting quality (difference of $0.269, p=0.036$ ).

\section{Figure 4. Marginal effects of time horizon on reporting quality (95\% CIs; planned additional test)}

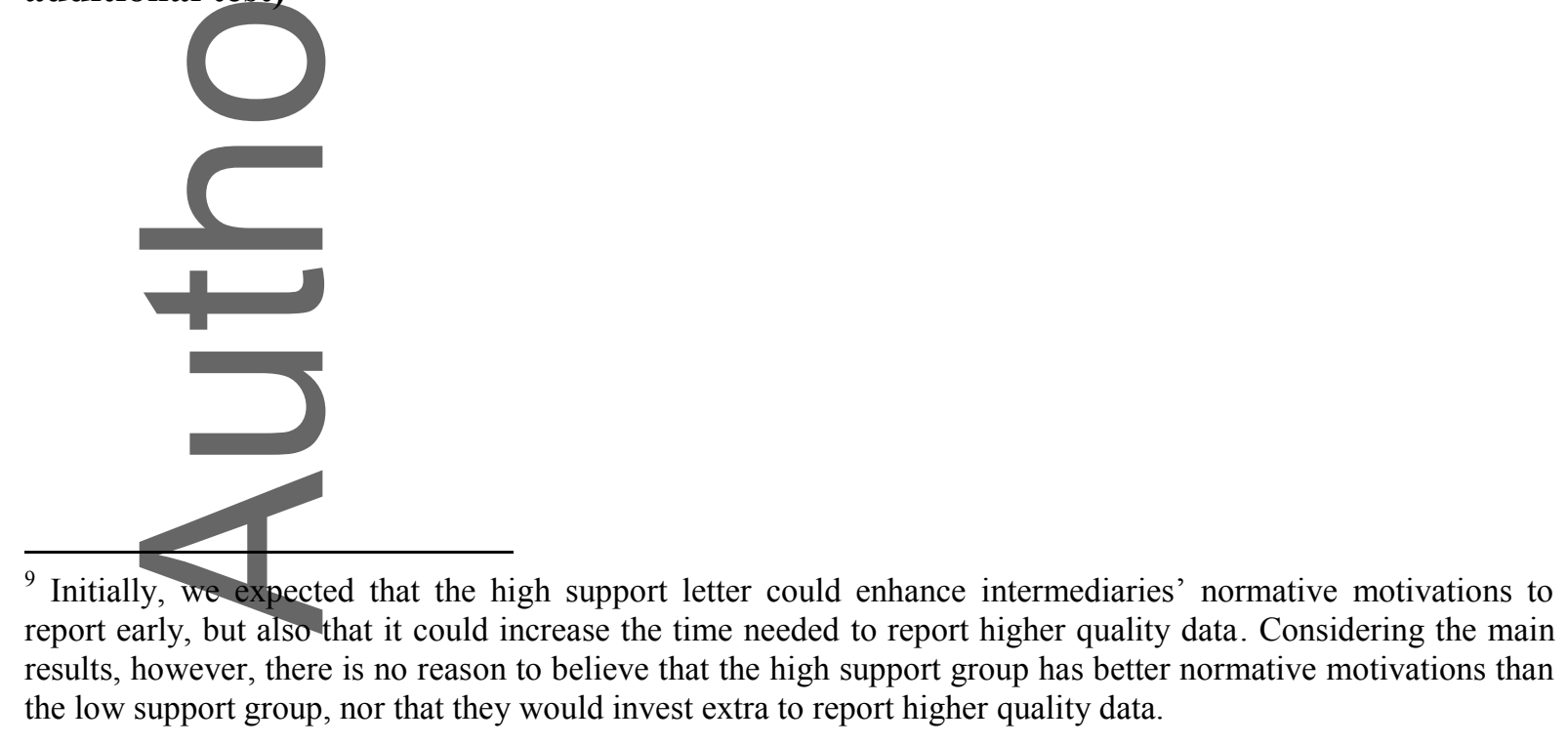

This article is protected by copyright. All rights reserved. 


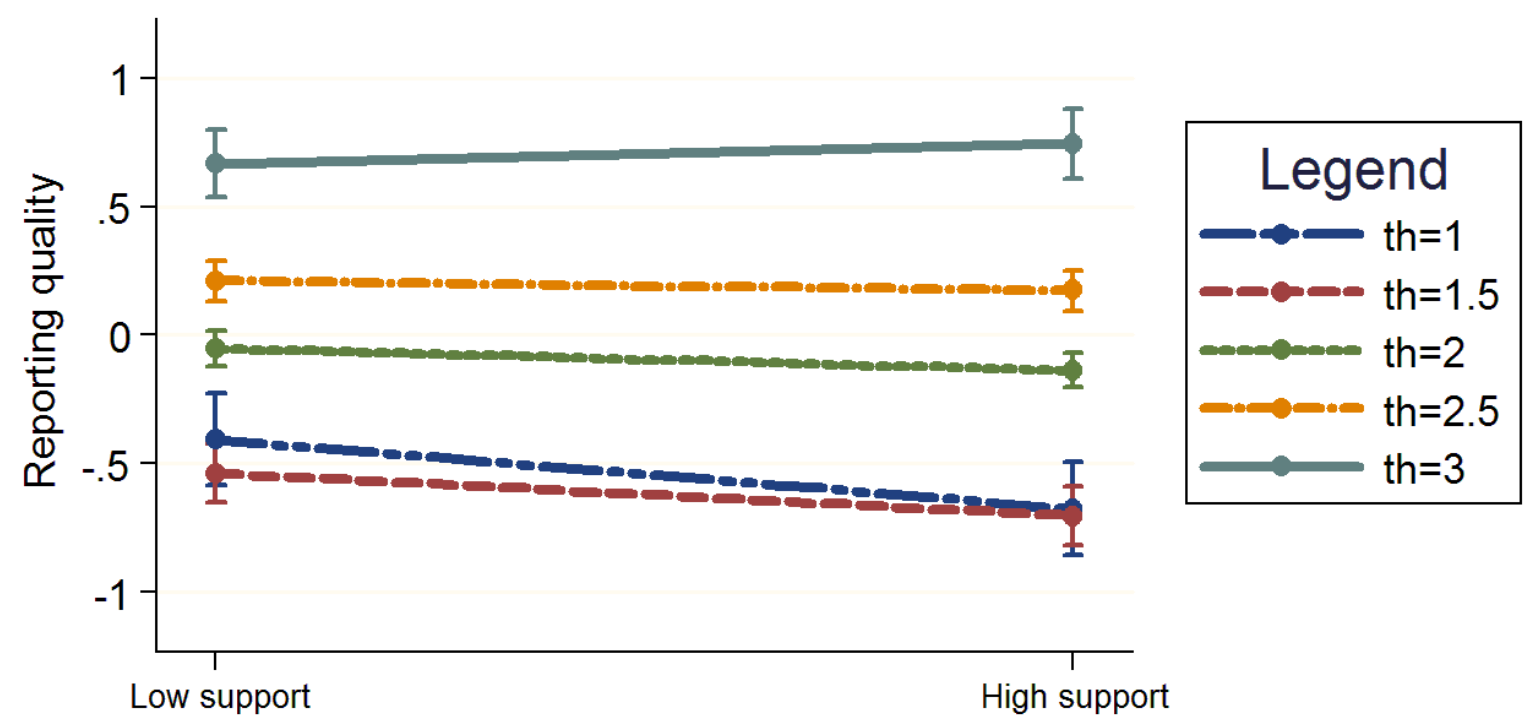

F. Effort in responding. Higher quality reporting is expected to be more time-consuming. However, efficient preparation and well-organized (and precise) information systems can decrease the time needed to complete the MM. We examine in this planned additional test how our treatment influences the self-reported time for preparing and completing the MM (number of hours; item 8.5 in the MM), and the time firms actually spent online to complete the MM as recorded by the AFM. Due to the skewed distributions of these variables, we logtransform them. ${ }^{10}$

On average, the high support group reported that they needed $3.87\left(\mathrm{e}^{1.352}\right)$ hours to prepare and complete the MM, while the low support group reported a time spending of 3.86 $\left(\mathrm{e}^{1.351}\right)$ hours. AFM records show that the high support group spent on average 1.59 hours online, and the low support group on average 1.65 hours. These differences are not significant. We conduct OLS regression analyses on both variables (Table 9, columns 2 and 3 ). The F-test of the regression model for recorded online time is not significant, and we refrain from drawing inferences from the results. Results for self-reported time confirm the results of the $t$-tests that there is no difference between treatment conditions. Firm size $(p<$ $0.01)$ and long-term orientation $(p<0.10)$ are positively associated with self-reported time,

\footnotetext{
${ }^{10}$ We did not propose a logarithmic transformation. However, as we gathered the data, we learned that there is a noise in the recorded online time (e.g., people leaving the screen open without working on the MM). To decrease the impact of this noise and to normalize the distribution, we apply a logarithmic transformation.
}

This article is protected by copyright. All rights reserved. 
which converges with the earlier finding that larger and long-term oriented firms deliver higher reporting quality.

Table 9. Results (planned additional) tests D - G

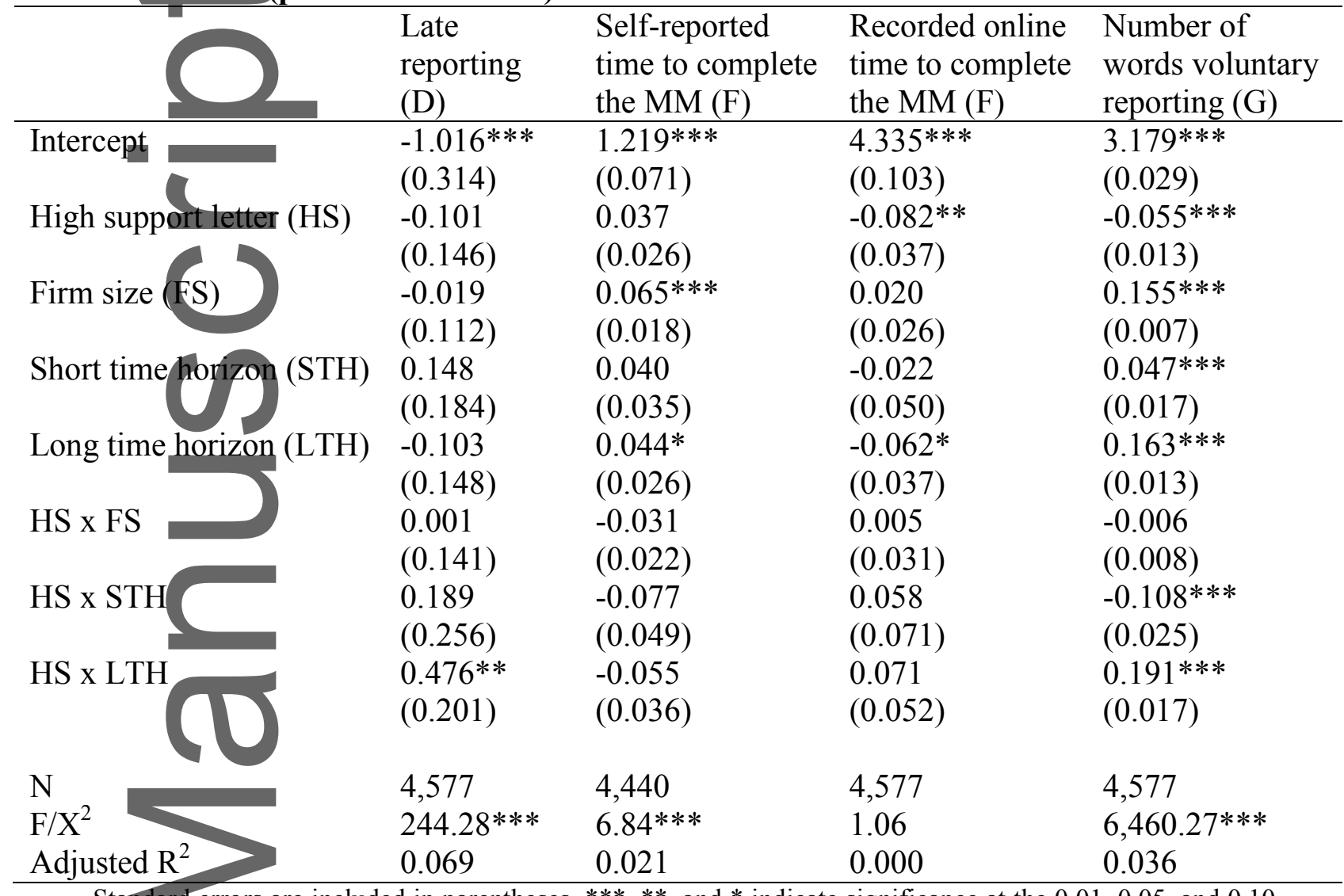

Standard errors are included in parentheses. ${ }^{* *}, * *$, and $*$ indicate significance at the $0.01,0.05$, and 0.10 level (two-tailed), respectively. We registered tests D, F, and G in our proposal.

G. Extensiveness of voluntary reporting. We proposed as potential alternative measure of voluntary reporting the number of words submitted in item 1.18, which robustness test was conditional on obtaining access to these data. We were able to obtain these data and replaced the voluntary reporting indicator with this measure of extensiveness of voluntary reporting to redo all planned-analyses. This provides similar results as reported, with two exceptions. First, in line with the results of our main analyses, results (Table 9, column 4) show that firms with a low support letter on average provided more words than firms with a high support letter $(\beta=-0.055, p<0.01)$. Long-term oriented firms receiving a high support letter provide more extensive responses $(\beta=0.191, p<0.01)$, while short-term oriented firms receiving a high support letter provide the shortest $(\beta=-0.108, p<0.01)$. The results of this planned additional test thus provide support for the antagonizing interaction predicted in Hypothesis 
3: the high support letter induces more extensive voluntary reporting for long-term oriented firms, while it does the opposite for short-term oriented firms.

Second, in analyses that employ the recalculated measure of reporting quality (i.e., using the extensiveness of voluntary reporting), we similarly find in the test that employs the 5level categorical time horizon measure (similar to test E) evidence for the predicted antagonizing interaction effect: high support increases reporting quality for long-term oriented firms $(p=0.046)$, and reduces reporting quality for short-term oriented firms $(p=$ 0.016).

H. Perceived inconsistency between the high support and reminder letters. We conduct two unplanned additional tests because of the significant proportion of firms that received a first reminder letter one week before the reporting deadline. ${ }^{11}$ The high support letter may have evoked a weaker sense of obligation and urgency to report in time, which is in contrast to the tone of the reminder letter. Firms in the high support group receiving a reminder letter may have perceived an inconsistency which could enhance perceptions of unfairness and translate into lower reporting quality. To examine the effects of this potential inconsistency on reporting quality and perceptions of informational fairness, we conduct two unplanned additional tests. These tests use the same explanatory variables as those reported in Table 6, plus (i) a dummy variable taking the value 1 if the firm received a reminder letter and 0 otherwise, and (ii) its interaction with the high support letter dummy. A negative and significant interaction effect would indicate that firms receiving these two letters react negatively to potentially inconsistent messages. Untabulated results show this interaction term is associated with neither overall reporting quality $(\beta=-0.025, p=0.792)$ nor informational fairness $(\beta=0.052, p=0.173)$, indicating no significant differences induced by the reminder letter.

\section{Conclusion}

In collaboration with the Authority for Financial Markets (AFM) in the Netherlands, we conduct a field experiment to examine whether official communication that reflects a supportive regulatory strategy influences the quality of the information reported in a mandatory self-assessment, which is called Market Monitor (MM). Official communications (instructional letters containing information about the invitation, username, and password to complete and submit the MM) are manipulated in three ways. Letters that reflect a high support strategy (high support letter) have a supportive tone (tone), explain the objectives of the MM and how these align with the objectives of the firm (purpose), and signal a strong willingness of the AFM to help firms complete the MM (accessibility). In a low support

\footnotetext{
${ }^{11}$ We thank the reviewer for suggesting these additional tests.
}

This article is protected by copyright. All rights reserved. 
letter, in contrast, the tone is distant, formal and authoritative; firms are not informed about the goals of the MM, and the communicated willingness to help firms is low.

We hypothesize that (1) a high support letter is positively associated with firms' reporting quality, (2) firm size weakens this positive association, and (3) a long-term orientation enhanees this association, while a short-term orientation reverses it (so that the effect becomes negative). In the planned main analyses, we find no evidence indicating that the high support letter induces higher reporting quality, or that this effect is moderated by firm size, although firm size directly influences reporting quality. The planned main and additional analyses provide partial evidence for the third hypothesis. Firms with a long-term orientation have higher reporting quality than firms with a medium or short-term orientation, and as compared to these firms, show no decrease in reporting quality when receiving a high support letter. If we replace the use of voluntary reporting for the extensiveness of voluntary reporting, we find evidence for the predicted antagonistic effect, where the high support letter has a positive (negative) effect for firms with a long (short) time horizon. These results jointly suggest that, in order to obtain high quality information in self-reports, the authority benefits from a high support letter only if firms have a long-term orientation.

In general, it is believed that authorities benefit from more support-based regulatory strategies. We do not find support for that position in this industry. A possible explanation is that in the relationship between the AFM and intermediaries, insufficient trust has been developed to accommodate such a strategy. A survey of Baarsma, Risseeeuw, and Rosenboom [2012] among financial intermediaries found they were critical about the way in which the AFM supervised the market (but not towards supervision in general). Intermediaries also indicated in this survey they were not convinced that the information collected by the AFM was useful for supervision. While the nature of self-reporting and the AFM's information demands have changed since then, intermediaries may still not be convinced of the objective of the MM, may not feel the AFM is able to easily detect misreporting, and may in general have negative motivational postures. If motivational postures are on average already negative, a supportive strategy may not help to enhance reporting quality. In contrast, compared to receiving a high support letter, intermediaries receiving a low support letter may interpret the stricter tone and low accessibility as an indication that reporting high quality data is a regulatory obligation. This could explain why 
the low support letter does not perform worse in this setting. Our finding of a differential impact of the two letters for long-term oriented firms, supports the expectation that especially those who value future interactions with the regulator are more strongly influenced by a supportive regulatory strategy.

Our results contribute to different streams of literature. First, we contribute to the theory of respensive regulation by providing evidence that reporting quality differs for firms with different time horizons, and that these differences can increase depending on the regulatory style that is communicated to these firms. In addition, while there is a general positive stance towards supportive regulatory strategies and the benefits they can provide, our findings provide no eyidence of a direct positive effect on firms' reporting quality. This may relate to the nature of the industry and the relationship between supervisor and market participants, which seem to be important in considering the effects of such strategies. Second, the results of our study contribute to the literature of regulatory reporting in which field experiments are rare. We demonstrate that communication alone may have an effect on reporting quality without actual differences in regulatory strategy. This suggests that adapting responsive regulation strategies across a wider setting of interactions between a supervisor and subsets of firms may have stronger effects.

Our findings have three practical implications. First, they show that time horizon is associated with firms' reporting behavior. Authorities may use this insight to differentiate between firms with different time horizons and, for instance, target quality checks on selfassessment data particularly at short-term oriented firms. Second, our findings show that the effect of a high support letter on reporting quality differs with firms' time horizon. Authorities employing self-reporting as part of their regulatory strategy may want to examine firms' time horizon to decide how to present themselves in official communications, and in considering their supervision strategy and regulatory actions. Third, a high support strategy does not come without risks. For example, a high support letter may evoke a weaker sense of urgency and obligation, or send signals of weak enforcement capacity. Authorities thus need to carefully consider when and for whom such strategies can effectively be adopted.

Despite the fact that we find support for differentiating communication dependent on firms' time horizon, several challenges remain. In the industry that we study, the intermediaries might on average still not perceive the information that is collected by the 
Market Monitor as highly valuable. This implies that the regulator could have a challenge to convince the market about the relevance beyond the content of the letter. The fact that the letter results in differences between firms is promising in the sense that targeted supervision has upside potential. Future research could provide regulatory authorities with more insight into the persistence of the observed effects. Re-using these letters may become standard after a certain period of time, potentially causing them to lose their effect. It may therefore be important to adapt a support-based strategy for targeted firms over a wider range of interactions. Future studies could also examine if and how other regulatory instruments, such as phone calls and audits, influence firms' reporting behavior. In addition, it may be highly relevant to examine to what extent reporting behavior is related to other behavioral outcomes, such as compliance with regulations. Examining the effects of low vs. high support letters on compliance, when these letters communicate the same requirements and expectations to firms, would provide valuable insights on how perceived support interacts with the sense of obligation

\section{References}

AFM. Strategische doelstellingen. Consulted on April 27, 2017 Available at: https://wwwarm.nl/nl-nl/over-afm/werkzaamheden/strategische-doelstellingen.

ALFORD, J., and R. SPEED. 'Client focus in regulatory agencies: Oxymoron or opportunity?’ Public Management Review 8 (2006): 313 - 331.

ARIEL, B. 'Deterrence and moral persuasion effects on corporate tax compliance: Findings from a randomized controlled trial.' Criminology 50 (2012): 27 - 69.

BALAKRISHNAN, K., CORE, J.E., and R.S. VERDI. 'The relation between reporting quality and financing and investment: Evidence from changes in financial capacity.' Journal of Accounting Research 52 (2014): 1 - 36.

BAARSMA, B., RISSEEUW, P. and N. ROSENBOOM. 'Het moet van twee kanten komen. Financieel adviseurs over hun toezichthouder.' (2012). SEO report nr. 2012 - 33.

BARON, D.P., and R.B. MYERSON. 'Regulating a monopolist with unknown costs.' Econometrica 50 (1982): 911-930.

BENFORD, F. 'The law of anomalous numbers.' Proceedings of the American Philosophical Society 78 (1938): 551-572.

BESANKO, D., and D.E.M. SAPPINGTON. 'Designing Regulatory Policy with Limited Information.' Fundamentals of Pure and Applied Economics 20, Harvard Academic Publishers 1987.

BIDDLE, G.C., HILLARY, G., and R.S. VERDI. 'How does financial reporting quality relate to investment efficiency?' Journal of Accounting and Economics 48 (2009): 112 131. 
BLUMENTHAL, M., CHRISTIAN, C., and J. SLEMROD. 'Do normative appeals affect tax compliance? Evidence from a controlled experiment in Minnesota.' National Tax Journal 54 (2001): $125-136$.

BRAITHWAITE,V. 'Dancing with tax authorities: Motivational postures and noncompliant actions,' in: Taxing democracy. Understanding tax avoidance and tax evasion. Edited by V. Braithwaite. Aldershot, UK: Ashgate, 2003: 15-39.

BRAITHW AITE, V. 'Responsive regulation and taxation: Introduction.' Law \& Policy 29 (2007): $3-10$.

CARSLAW, C.A.P.N. 'Anomalies in income numbers: Evidence of goal oriented behavior.' The Accounting Review 62 (1988): 321-327

CASTRO, L., and C. SCARTASCINI. 'Tax compliance and enforcement in the pampas evidence from a field experiment.' Journal of Economic Behavior \& Organization 116 (2015): $65-82$.

CHOO, C.Y.L., FONSECA, M.A., and G.D. MYLES. 'Do students behave like real taxpayers in the lab? Evidence from a real effort tax compliance experiment.' Journal of Economic Behavior \& Organization 124 (2016): 102-114.

COHEN, J. 'A power primer.' Psychological Bulletin 112 (1992): 155 - 158.

COLQUITT, J.A., CONLON, D.E., WESSON, M.J., PORTER, C.O.L.H., and K. YEE. 'Justice at the millennium: A meta-analytic review of 25 years of organizational justice research.' Journal of Applied Psychology 86 (2001): 425 - 445.

DURTSCHI, C., HILISON, W., and C. PACINI. 'The effective use of Benford's Law to assist in detecting fraud in accounting data.' Journal of Forensic Accounting 5 (2004): $17-$ 34.

ERNST and YOUNG. 'Setting the pace of change. 2011 federal reserve: Bank regulatory reporting survey.' (2012). Consulted on April 4, 2016. Available at: http://www.ey.com/Publication/vwLUAssets/Federal_Reserve: bank_regulatory_reportin g_survey/\$FHLE/ErnstYoungFRBsurveyreportfinal.pdf.

FAIRMAN, R., and C. YAPP. 'Enforced self-regulation, prescription, and conceptions of compliance within small businesses: The impact of enforcement.' Law \& Policy 27 (2005): 491-519.

FELLNER, G., SAUSGRUBER, C., and TAXLER, C. 'Testing enforcement strategies in the field: Threat, moral appeal and social information.' Journal of the European Economic Association 11 (2013): $634-660$.

FRIESEN, L., and L. GANGADHARAN. 'Designing self-reporting regimes to encourage truth telling: An experimental study.' Journal of Economic Behavior \& Organization 94 (2013):90-102.

GREENBERG, J. 'Using socially fair treatment to promote acceptance of a work site smoking ban.'Journal of Applied Psychology 79 (1994): 288 - 297.

HALLSWORTH, M. 'The use of field experiments to increase tax compliance.' Oxford Review of Economic Policy 30 (2014): 658 - 679.

HALLSWORTH, M., LIST, J.A., METCALFE, R.D., and I. VLAEV. 'The behavioralist as tax collector: Using natural field experiments to enhance tax compliance.' Journal of Public Economics 148 (2017): 14 - 31.

HASSELDINE, J., HITE, P., JAMES, S., and M. TOUMI. 'Persuasive communications: Tax compliance enforcement strategies for sole proprietors.' Contemporary Accounting Research 24 (2007): 171 - 194. 
HEALY, J., and J. BRAITHWAITE. 'Designing safer health care through responsive regulation.' Medical Journal of Australia 184 (2006): S56 - S59.

HEYES, A. 'Implementing environmental regulation: Enforcement and compliance.' Journal of regulatory economics 17 (2000): 107-129.

HILL, T.P. 'A statistical derivation of the significant-digit law.' Statistical Science 10 (1995): 354-363.

HOFMANN, E., HOELZL, E., and E. KIRCHLER. 'Preconditions of voluntary tax compliance.' Journal of Psychology 216 (2008): 209 - 217.

INDERST, R., and M. OTTAVIANI. 'Misselling through agents.' American Economic Review 99 (2009): 883 - 908.

KAPLOW, L., and S. SHAVELL. 'Optimal law enforcement with self-reporting of behavior.' Journal of Political Economy 102 (1994): 583-606.

KIRCHLER, E., HOELZL, E., and I. WAHL. 'Enforced versus voluntary tax compliance: The "Slippery Slope" framework.' Journal of Economic Psychology 29 (2008): 210-225.

LEUZ, C. and P. WYSOCKI. 'The economics of disclosure and financial reporting regulation: Evidence and suggestions for future research.' Journal of Accounting Research 54 (2016): $525-622$.

LINDEBOOM, M., VAN DER KLAAUW, B., and S. VRIEND. 'Audit rates and compliance: A field experiment in care provision.' Journal of Economic Behavior and Organization 131 (2016): 160 - 173.

LIST, J.A., SHAIKH, A.M., and Y. XU. 'Multiple hypothesis testing in experimental economics.' NBER Working Paper 21875, 2016. Available at: http://www.nber.org/papers/w21875.

LOEWENSTEIN, G., and R. THALER. 'Anomalies: Intertemporal choice.' Journal of Economic Perspectives 3 (1989): 181-193.

MAY, P.J, and S.C. WINTER. 'Regulatory enforcement styles and compliance,' in: Explaining regulatory compliance. Businesses responses to regulation. Edited by $\mathrm{C}$. Parker and V.L. Nielsen. Edward Elgar Publishing Inc, USA: Massachusetts, 2011: 222 244.

MALLOY, T.F. 'Regulation, compliance and the firm.' Temple Law Review 76 (2003): 451532.

MENDOZA, J.P., DEKKER, H.C., and J.L. WIELHOUWER. 'Firm's Compliance with Complex Regulations.' Law and Human Behavior 40 (2016): 721 - 733.

MENDOZA, J.P., and J.L. WIELHOUWER. 'Only the carrot, not the stick: Incorporating trust in the enforcement of regulation.' PLoSONE 10 (2015): e0117212. Available at: http://journals.plos.org/plosone/article?id=10.1371/journal.pone.0117212.

NIELSEN, V.L. and C. PARKER. 'Mixed motives: Economic, social and normative motivations in business compliance.' Law and Policy 34 (2012): 428 - 462.

NIGRINI, M.J. A taxpayer compliance application of Benford's law.' Journal of the American Taxation Association 18 (1996): 72-91.

PARKER, C. 'The open corporation: effective self-regulation and democracy'. Cambridge University Press, UK: Cambridge 2002.

PARKER, C., and V.L. NIELSEN. 'Explaining compliance: Business responses to regutation.' Edward Elgar Publishing Inc, USA: Massachusetts (2011).

PAUTZ, M., and S. RINFRET. 'State environmental regulators: Perspectives about trust with their regulatory counterparts.' Journal of Public Affairs 16 (2016): 28 - 38. 
PEETERS, M. 'Inspection and market-based regulation through emissions trading. The striking reliance on self-monitoring, self-reporting and verification.' Utrecht Law Review 2 (2006): $177-195$.

SAPPINGTON, D.E.M. 'Optimal regulation of research and development under imperfect information.' The Bell Journal of Economics 13 (1982): 354-368.

SMITH, K.W. 'Reciprocity and fairness: Positive incentives for tax compliance' in: Why people pay taxes - Tax compliance and enforcement. Edited by J. Slemrod. University of Michigan Press, USA: Ann Arbor 1992: 223-258.

SMITH, K.W., and L.J. STALANS. 'Encouraging tax compliance with positive incentives: A conceptual framework and research directions.' Law \& Policy 13 (1991): 35-53.

SINCLAIR, D. 'Self-regulation versus command and control? Beyond false dichotomies.' Law \& Policy 19 (1997): 529-559.

TORGLER, B. 'Moral suasion: An alternative tax policy strategy? Evidence from a controlled field experiment in Switzerland.' Economics of Governance 5 (2004): 235 253.

TYLER, T.R. 'Why do people obey the law.' Princeton University Press, USA and UK: Princeton and Oxford, 2006.

WENZEL, M. 'Tax compliance and the psychology of justice: Mapping the field,' in: Taxing Democracy. Edited by Braithwaite, V. UK: Aldershot, England: Ashgate Publishing, 2003: $55-69$.

WENZEL-M., and N. TAYLOR. 'An experimental evaluation of tax-reporting schedules: A case of evidence-based tax administration.' Journal of Public Economics 88 (2004): 2785 $-2799$

WENZEL, M. A letter from the tax office: Compliance effects of informational and interpersonal justice.' Social Justice Research 19 (2006): 345 - 364.

WHITMAN, D.S, CALEO, S., CARPENTER, N.C., HORNER, M.T., and J.B. BERNETH. 'Fairness at the collective level: A meta-analytic examination of the consequences and boundary conditions of organizational justice climate.' Journal of Applied Psychology 97 (2012): $776-791$.

\section{Appendix A. Translated Market Monitor questions}

This document provides translations of relevant questions in the Market Monitor, which we use to measure the dependent, moderating, and control variables of interest. The original Dutch Market Monitor (Marktmonitor Adviseurs en Bemiddelaars) is available upon request, and on the AFM's website (https://www.afm.nl/nl-nl/professionals/doelgroepen/adviseursbemiddelaars/thema/self-assessment).

\section{Item 1.2: Reason why you have been inactive last year (situation)}

You indicated that your firm did not provide financial services in part of 2016.

Which of the following situations applies to your firm?

Only one answer is possible

My firm started providing financial services in 2016 
My firm started providing financial services in 2017 (you only have to fill in the number of full time employees and assert that you completed the Market Monitor truthfully)

$\square$ My firm temporarily stopped providing advisory and mediation activities in 2016

$\square$ My firm has not started providing financial services yet (you only have to fill in the number of full time employees and assert that you completed the Market Monitor truthfully)

$\square$ My firm stopped providing financial services in 2016 and did not manage client portfolios, or was not actively providing financial services during 2016

Item 1.4: Product groups

For which product groups did your firm actively provide financial services in $2016 ?$

Multiple answers are possible

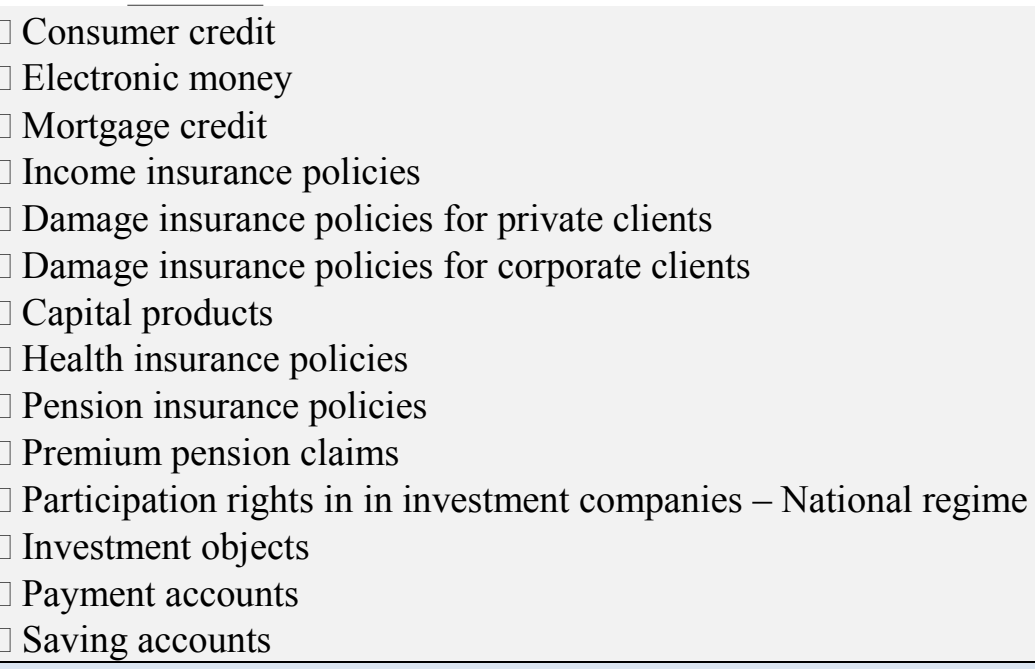

\section{Explanation:}

Your firm was actively providing financial services in 2016 if it advised, mediated, or provided services as an authorized agent for a product group or if it managed products of a particular product group from its portfolio. Having a license to operate for certain product groups does not necessarily mean that your firm was actively providing financial services for this product group. Your firm can have a license for a product group, but not use it actively in practice. In that case, your firm has not been active with that particular product group.

\section{Item 1.11: Franchise}

Was your firm a franchise holder or provider in 2016 ?

Only one answer is possible

$\square$ Yes, my firm is a franchise holder

$\square$ Yes, my firm is a franchise provider

$\square$ No 
Was your firm and/or one or more of your employees an affiliated member of a union, trade association, or content labeling and certification company in the sector of financial service providers?

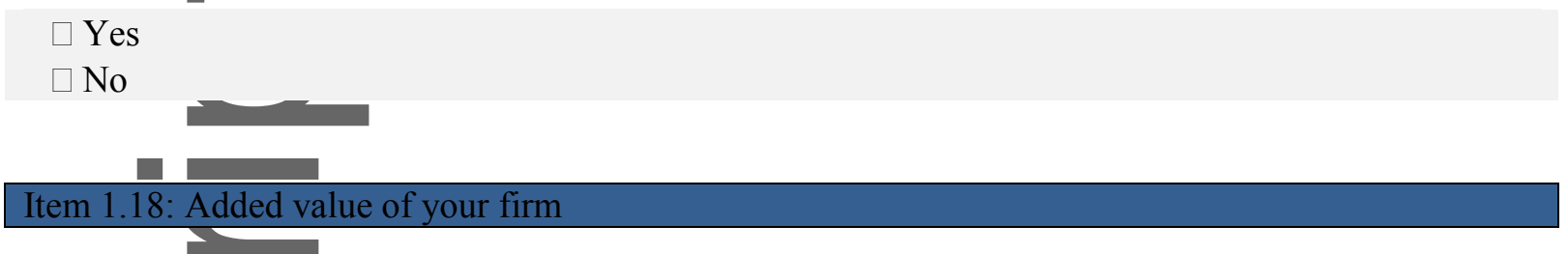

Advisors and intermediaries often indicate that they cannot sufficiently describe the character of their firm in the (standardized) Market Monitor. For example, because a firm is small or traditional, or because it serves a particular niche market. In order to facilitate you to describe your firm, we ask you this (non-compulsory) question. If you do not want to answer this question, you can indicate so, and continue with the next question.

We ask you to deseribe in a maximum of 250 words how your firm differentiated itself from fellow advisors and/or intermediaries in 2016.

Provide your answer

$\square$ I do not want to answer this question

Item 2.11: Number of clients

How many private and corporate clients did your firm's client portfolio contain on December 31, $2016 ?$

Fill in the number of clients (a rough estimation is sufficient)

Private clients

\section{Private clicits}

Corporate clients (including freelancers, DGA and collective arrangements)

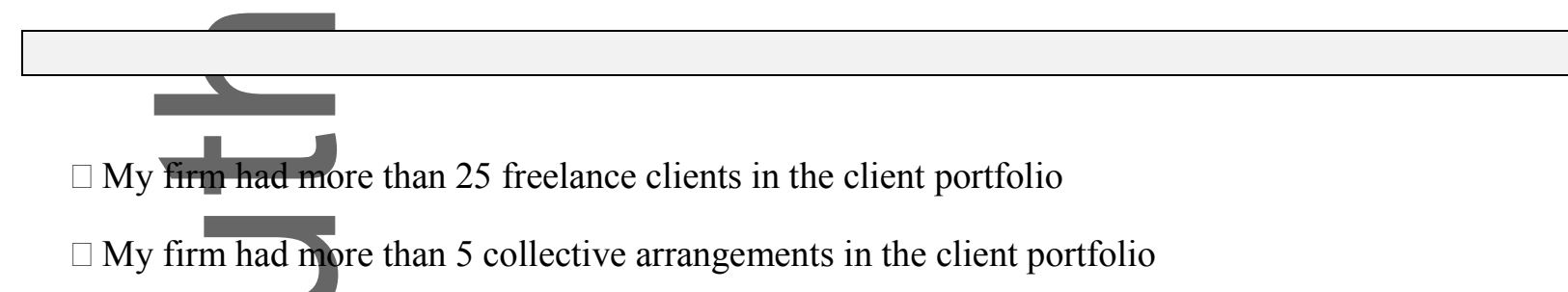

Explanation:

One collective arrangement is counted as one client. If you do not have any clients in one of the categories, fill in 0 . When you do not know the exact number of clients that your firm has, estimate it as accurately as possible. Pay attention to the following: if your firm has more than 25 freelance and/or more than 5 collective arrangements in its client portfolio, tick the corresponding box(es) above.

This article is protected by copyright. All rights reserved. 
Item 3.1: Type of employees

For each of the following statements, indicate if the situation applied to your firm in 2016.

One answer per statement

\begin{tabular}{|l|c|c|}
\multicolumn{1}{l}{ Yes } & No \\
\hline My firm had employees on payroll in 2016 & $\square$ & $\square$ \\
\hline My firm cooperated with freelancers in 2016 & $\square$ & $\square$ \\
\hline My firm cooperated with temporary employees in 2016 & $\square$ & $\square$ \\
\hline The employees of the firm were the owners of the firm & $\square$ & $\square$ \\
\hline
\end{tabular}

Item 3.2.1 - 4: Number of employees

You indicated that in 2016, your firm had employees on payroll and/or cooperated with freelancers and/or temporary employees.

State for each group, how many people were employed in your firm or cooperated with your firm between January 1,2016 and December 31, 2016.

Also state how many employees were hired and how many collaborations started in 2016.

Fill in the number of employees

January 1, $2016 \quad$ December 31, $2016 \quad$ Hired in 2016

\section{Employees involved in}

financial services

\begin{tabular}{|l|l|l|l|}
\hline Employees on payroll & & & \\
\hline Freelancers & & & \\
\hline Temporary employees & & & \\
\hline
\end{tabular}

Employees not

January 1, 2016

December 31, 2016

Hired in 2016

involved in financial

services

Total number of

employees

\section{Explanation:}

Pay attention to the following: Fill in the number of people, not the number of FTE. For example:

Two people who both work 20 hours per week count as two employees. If an employee distributes his or her activities over financial services and non-financial services, you can allocate this person to one type of activity based on your own knowledge. For example: if an employee spent 10 hours of his or her time on non-financial services and 30 hours on financial services, you should allocate the employee to 'employees involved in financial services'. Owners and/or policymakers, who work for the firm on another basis than payroll are disregarded. 
Do you expect the number of employees, freelancers and/or temporary employees in your firm to increase, decrease or be stable in the next year?

One answer possible

The number of employees, freelancers and/or temporary employees in my firm will increase r

$\square$ The number of employees, freelancers and/or temporary employees in my firm will remain stable

$\square$ The number of employees, freelancers and/or temporary employees in my firm will decrease

\section{Item 4.11: Number of new agreements through your firm}

You indicated that on December 31, 2016 your firm cooperated with service providers and/or authorized agents.

How many new agreements (not the prolongation of existing agreements) did you sell via service providers and/or authorized agents in 2016 ?

Indicate the number of agreements sold through service providers and/or authorized agents

Item 5.1: Number of advisory services provided

You indicated that your firm sold products in 2016 related to the service provision items below.

For each item, state how many advisory services your firm provided in 2016 (in terms of the Financial Supervision Act - Wet financieel toezicht).

Fill in the number of advisory services per item.

Mortgage request

Pension employer

Asset growth

Hedging risks (for impactful products or products with a commission ban)

Borrowing money

\begin{tabular}{l} 
Number of \\
advisory services \\
\hline$\#$ \\
\hline$\#$ \\
\hline$\#$ \\
\hline$\#$ \\
\hline$\#$ \\
\hline
\end{tabular}

\section{Explanation:}

If you cannot provide exact numbers, it is sufficient to provide an estimation.

It is not relevant for this question whether the client followed the advice and the advice resulted in a sale.

You can also consult the definition of advisory services (in terms of the Financial Supervision Act Wet financieel toezicht) in the glossary. WGA and WIA insurances are not included in the service provision item 'hedging risks'. 
You indicated that your firm provided mediation services in 2016 for products related to the product groups below.

How many produets did your firm successfully provide mediation services with in 2016 ?

Fill in the number for each product group.

Investment properties

Consumer credit

Mortgage credit

Income insurance policies (excl. occupational disability insurance policies)

Occupational disability insurance policies

Damage insurances for private clients

Damage insurances for corporate clients

Capital (excl. investment insurance policies, life insurance policies, and funeral insurance policies)

Investment insurance policies

Life insurance policies

Funeral insurance policies

Health insurance policies

Pension insurance policies

Premium pension claims

$\begin{aligned} & \text { Number of } \\
& \text { products sold }\end{aligned}$
\begin{tabular}{|l|}
\hline$\#$ \\
\hline$\#$ \\
\hline$\#$ \\
\hline$\#$ \\
\hline$\#$ \\
\hline$\#$ \\
\hline$\#$ \\
\hline$\#$ \\
\hline$\#$ \\
\hline$\#$ \\
\hline$\#$ \\
\hline$\#$ \\
\hline$\#$ \\
\hline$\#$ \\
\hline
\end{tabular}

\section{Explanation:}

If you cannot specify exact numbers, it is sufficient to provide an estimation.

Does your firm bundle insurance policies in packages which you cannot specify separately? Try to determine an average number of policies per package.

For example: Suppose your firm has 1,000 damage insurance policies, of which 200 are bundled, and on average a bundled package has 2.5 policies. Then you fill in: $800+(200 * 2.5)=1,300$ policies.

\section{Item 5.5: Management of products}

You indicated that your firm managed products for clients that are related to the product groups

below.

How many products did your firm manage on December 31, 2016?

Fill in the number for each product group.

Consumer credit

Mortgage credit

Income insurance policies (excl. occupational disability insurance policies)

Occupational disability insurance policies

Damage insurances for private clients

$\begin{aligned} & \text { Number of } \\
& \text { products in } \\
& \text { management }\end{aligned}$
\begin{tabular}{|l|}
\hline$\#$ \\
\hline$\#$ \\
\hline$\#$ \\
\hline$\#$ \\
\hline$\#$ \\
\hline
\end{tabular}

This article is protected by copyright. All rights reserved. 
Damage insurances for corporate clients

Capital (excl. investment insurance policies, life insurance policies, and funeral insurance policies)

Investment insurance policies

Life insurance policies

Funeral insurance policies

Health insurance policies

Pension insurance policies

Premium pension claims

Investment properties

\begin{tabular}{|l|}
\hline$\#$ \\
\hline$\#$ \\
\hline$\#$ \\
\hline$\#$ \\
\hline$\#$ \\
\hline$\#$ \\
\hline$\#$ \\
\hline$\#$ \\
\hline$\#$ \\
\hline
\end{tabular}

\section{Explanation:}

If you cannot specify exact numbers, it is sufficient to provide an estimation.

Does your firm bundle insurance policies in packages which you cannot specify separately? Try to determine an average number of policies per package.

For example: Suppose your firm has 1,000 damage insurance policies, of which 200 are bundled, and on average a bundled package has 2.5 policies. Then you fill in: $800+(200 * 2.5)=1,300$ policies.

\section{Item 5.10: Total sales of financial activities billed}

Indicate the total amount of sales* (other than provision and commission) that your firm billed to clients for providing advisory, mediation and management services in 2016. Exclude the total amount billed for affercare and service subscriptions.

\section{- * Including VAT}

- Excluding (provider) premium

- Excluding provision and commission

- Excluding aftercare and service subscriptions

Fill in the amount per product group (Round up to integers in Euros)

Consumer credit

Mortgage credit

Income insurance policies (excl. occupational disability insurance policies)

Occupational disability insurance policies

Damage insurances for private clients

Damage insurances for corporate clients

Capital (excl. investment insurance policies, life insurance policies, and funeral insurance policies)

Investment insurance policies

Life insurance policies

Funeral insurance policies

Health insurance policies

Pension insurance policies

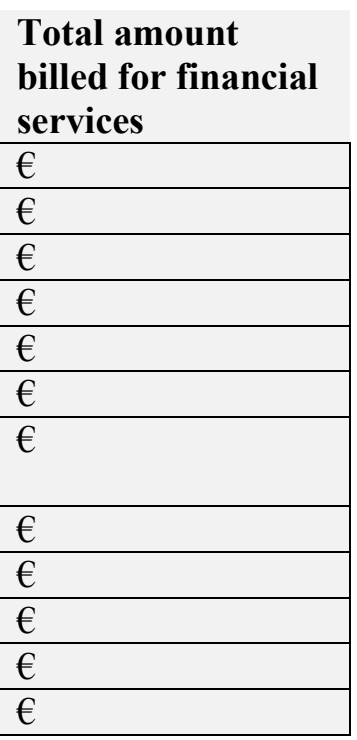

This article is protected by copyright. All rights reserved. 
Premium pension claims

Participation rights in investment companies - National regime

\begin{tabular}{|l|}
\hline$€$ \\
\hline$€$ \\
\hline
\end{tabular}

\section{Explanation:}

If you simultaneously charged your client for services related to multiple product groups, it is sufficient to provide an estimation of the billed amounts for different product groups. If your firm only received provisions and/or commissions, fill in 0 .

\section{Item 5.11: Provision of mediation services}

You indicated that your firm provided mediation services in 2016 for the product groups below. Furthermore, you indicated that your firm is compensated for these services through provisions from the providers of financial products.

Provide the total amount of provisions per product group that your firm received in 2016 from providers of financial products (or others than the final client).

Fill in the amount per product group (Round up to integers in Euros)

Consumer credit

Mortgage credit

Income insurance policies (excl. occupational disability insurance policies)

Occupational disability insurance policies

Damage insurances for private clients

Damage insurances for corporate clients

Capital (excl. investment insurance policies, life insurance policies, and funeral insurance policies)

Investment insurance policies

Life insurance policies

Funeral insurance policies

Health insurance policies

Pension insurance policies

Premium pension claims

Participation rights in investment companies - National regime

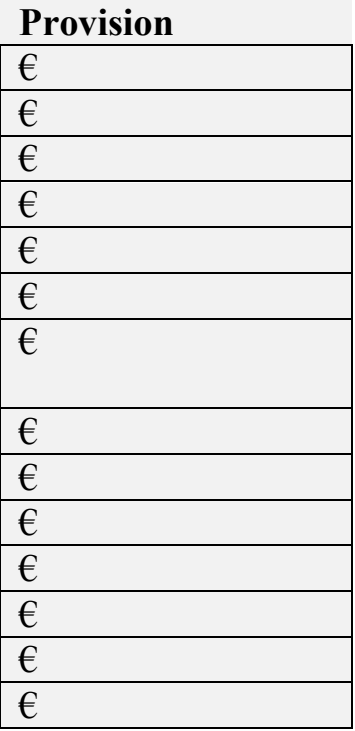

(* and excluding insurance taxes)

\section{Explanation:}

If you do not know the exact amount of provisions that your firm received, estimate the received provisions as accurately as possible.

\section{Item 5.18: Expectation of sales of advice/mediation services}

Do you expect the sales of advisory, mediation and/or other services provided by your firm to increase, decrease or be stable in 2017 ?

Only one answer possible

This article is protected by copyright. All rights reserved. 
$\square$ Sales of advisory, mediation and/or other services provided by my firm will increase

Sales of advisory, mediation and/or other services provided by my firm will remain stable

Sales of advisory, mediation and/or other services provided by my firm will decrease

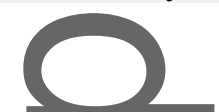

Item 6.1: Sales of financial services

What were your firm's (gross) sales from providing financial services in $2016 ?$

Fill in the sales below (round up to integers in Euros)

$€$

\section{Explanation:}

If you do not know the exact amount of sales, estimate it as accurately as possible.

\section{Item 6.2: Sales of other services}

You indicated that your firm is also active in selling services other than financial services.

What were your firm's (gross) sales of other services in 2016 ?

Fill in the sales below (Round up to whole euros)

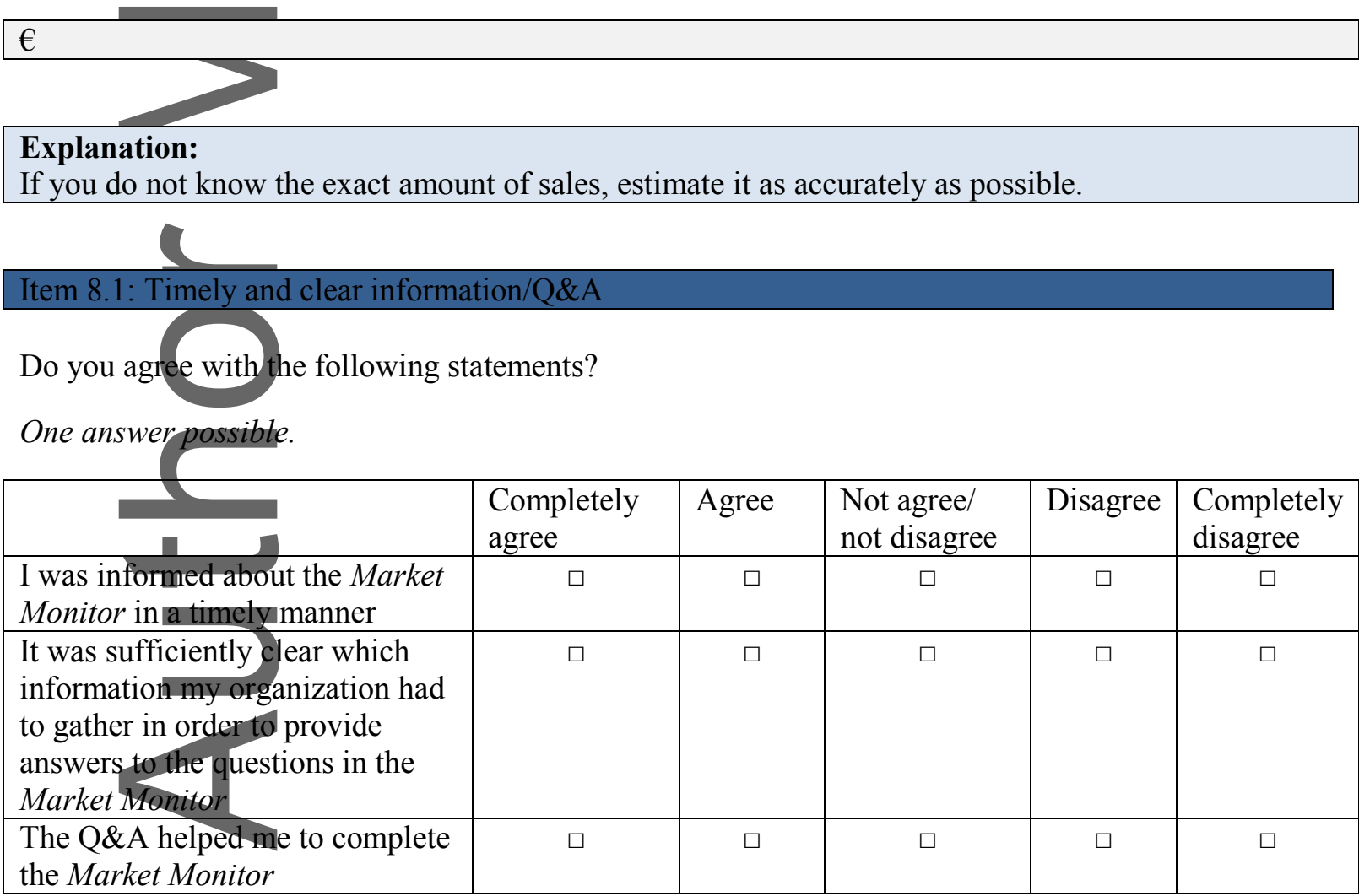

This article is protected by copyright. All rights reserved. 


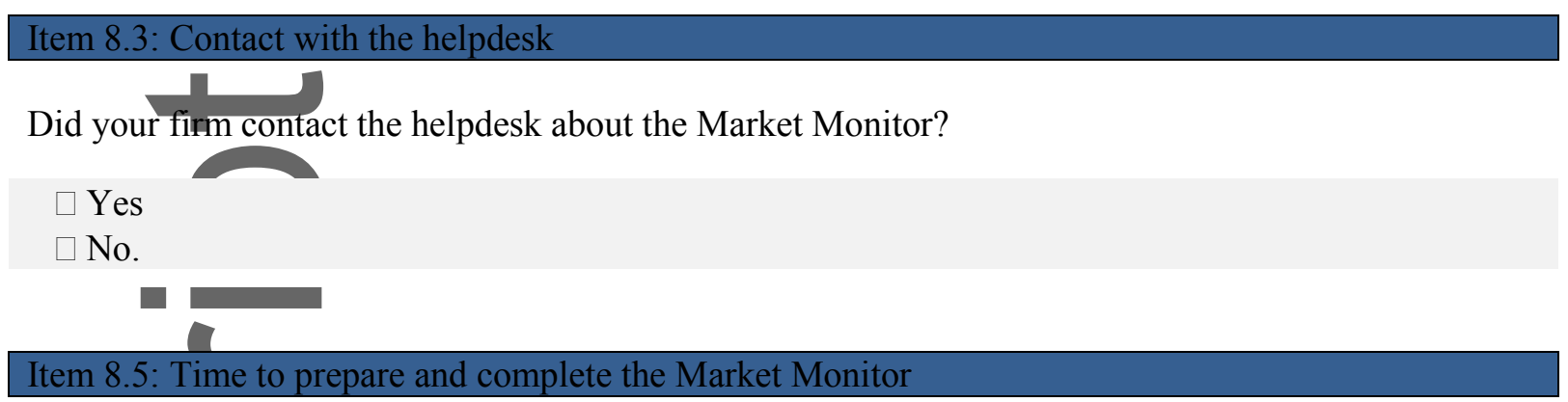

How much time did your firm need to prepare and complete the Market Monitor?

Fill in the total number of hours below

\#

\section{Appendix B.Translated instruction letters}

Note: The original Dutch letters are available upon request.

\section{High support}

Instruction letter

Subject: Announcement 2017 Market Monitor for intermediaries

Dear Sir, Madam,

\section{Announcement}

The Authority for Financial Markets (AFM) requests all intermediaries with a license to complete a questionnaire every year. This questionnaire is called the Market Monitor. With this letter, we want to inform you that you will soon receive the invitation to participate in the 2017 Market Monitor.

We realize that completing the yearly questionnaire requires a lot of your time and attention. We would like to support you in this and with this letter already inform you about the questionnaire and practical issues regarding its completion. Below you will find the date from which you can start completing the questionnaire, information on the available time to complete it, and information on what you can do to prepare.

The Market Monitor contributes to a well-functioning market for intermediaries The Market Monitor is important for the supervision activities of the AFM. With our supervision activities we aim for, among other things, honest and transparent financial 
markets. The information that intermediaries provide, helps us to get a better insight into this market. This allows us to target the AFM's supervision to risks and trends in the market or developments within individual firms. The information therefore contributes to a wellfunctioning market for intermediaries. For this goal, your contribution of accurately and timely completing the Market Monitor is important.

\section{Request supervision fees measure}

As last year, the request for the "supervision fee measure" is included in the Market Monitor. With your responses, the AFM assesses the 2017 supervision fees for your firm. This year, there is a possibility to choose the most appropriate measurement basis for your firm:

- The number of fulltime employees at December 31 of the previous year

- The average number of fulltime employees over the previous year. This average is calculated by adding the number of fulltime employees at March 31, June 30, September 30, and December 31 and dividing the obtained number by 4 .

More information is available in the Market Monitor.

Did your firm reyoke its AFM-license in 2017?

Even if your firm revoked its AFM license in 2017, it is necessary to complete the Market Monitor. In this ease, we limited the number of questions you need to complete. One of the questions concerns the measurement basis for supervision fees.

\section{Your data is handled confidentially}

We treat your data confidentially. This implies, among other things, that when we share data with thirdparties (for example in the form of publications of market analyses), it is never possible, nor allowed, to trace data back to your firm. If the AFM shares information about the Market Monitor with the public or third parties via, for example, electronic news letters about intermediaries, this will only be on market level.

When can you complete the questionnaire and how much time do you have to do that? If you have any questions, we would like to help you as quickly and as effectively as possible. To be better accessible for your questions, we divided all, approximately 7.500, intermediaries who participate in the Market Monitor in three groups. This improves our accessibility in case of questions. Your firm is in group [X].

We open your questionnaire on [DATE]. You have five weeks to complete and submit the questionnatre. A number of days in advance you will receive the information that you need to $\log$ in (oneletter with your username and another letter with your password). With this information you can open, complete, and submit the questionnaire.

\section{We want to support you in preparing for the Market Monitor}

We realize that completing the yearly questionnaire requires a lot of your time and attention.

To support you as much as possible in preparing for the Market Monitor, we provided necessary information on our website www.afm.nl/marktmonitor-ab. Among other things, you will find a printed version of the questionnaire on this website. Please note that this is a concept version and that the final questionnaire may contain changes. 
Do you have any questions? We are here to help you!

As mentioned above, you can find more information about the 2017 Market Monitor at http://www.afm.nl/marktmonitor-ab. Of course, you can also contact 'het Ondernemersloket'. 'Het Ondernemersloket' can be reached on working days from 10.00 until 17.00 via phone number 0800-6800 680 (free of charge) or by e-mail (ondernemersloket@afm.nl).

We thank you in advance for completing the Market Monitor and for your contribution to a well-functioning market for financial intermediaries.

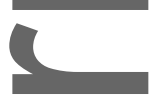

Kind regards,

The Authority for Financial Markets

First name Surname

First name Surname

Username letter

Subject: Invitation 2017 Market Monitor for intermediaries (with username)

Dear Sir, madam,

On [DATE] the Authority for Financial Markets (AFM) sent you a letter in which it announced the 2017 Market Monitor for intermediaries.

Via this letter, we send you the link and username you need to login. We also summarize other important information for you.

We want to be as accessible as possible in case you have questions. That is why we divided the, approximately 7.500, intermediaries who participate in the Market Monitor in three groups. Your firm is in group [X].

How do you complete the Market Monitor?

From [DATE] you can complete the questionnaire via www.afm.nl/marktmonitor-ab. In order to complete the questionnaire you need a username and a password. Please find the username below. You will receive the password in a separate letter within a few days.

Username: [Username]

Until which date do you have to complete the Market Monitor?

The deadline for your group is [DATE]. It is possible to save the questionnaire while you are working on it, so you do not have to complete the questionnaire at once.

We realize that completing the yearly questionnaire requires a lot of your time and attention. The information is important for us to maintain a well-functioning market for intermediaries. This is why it is important that you complete the Market Monitor timely, truthfully, and comprehensively.

We thank you in advance for your participation.

This article is protected by copyright. All rights reserved. 


\section{Questions? We are here to help you!}

We hope that you are already well-informed by the instruction letter and our website www.afm.nl/marktmonitor-ab, but of course we are available for help.

In case you have questions, you can contact 'het Ondernemersloket'. Het Ondernemersloket' can be reached on working days from 10.00 until 17.00 via phone number 0800-6800 680 (free of charge). 'Het Ondernemersloket' is also accessible via e-mail: ondernemersloket $@$ afm.nl.

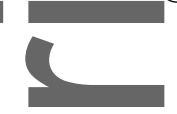

Kind regards,

The Authority for Financial Markets

First name Surname

First name Surname

Subject: Invitation Market Monitor for intermediaries 2017 (with password)

Dear Sir, Madam,

We informed you at an earlier stage about completing the 2017 Market Monitor. In a previous letter, you already received your username. In this letter, you receive your password so that you can start the questionnaire.

\section{Password: [Password]}

We want to remind you that it is possible to save your progress so that you do not have to complete the questionnaire at once.

You can complete the questionnaire from [DATE] until [DATE] via www.afm.nl/marktmonitor-ab.

\section{Questions? We are here to help!}

We hope that the instruction letter, letter with username, and www.afm.nl/marktmonitor-ab informed you sufficiently and in a timely manner. If you still have questions, our employees at the 'Ondernemersloket' are available for your questions. 'Het Ondernemersloket' can be reached on working days from 10.00 until 17.00 via phone number 0800-6800 680 (free of charge). 'Het Ondernemersloket' is also accessible via e-mail: ondernemersloket@afm.nl.

We thank you in advance for your cooperation and contribution to a well-functioning market for intermediaries.

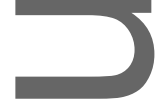

Kind regards,

The Authority for Financial Markets

First name Surname

First name Surname 


\section{Low support}

Instruction letter

Subject: Announcement 2017 Market Monitor for intermediaries

Dear Sir, Madam,

The Authority for Financial Markets (AFM) requests all intermediaries to complete a questionnaire every year. You will be invited to participate in the 2017 Market Monitor. It is legally required to complete this questionnaire.

Below you find more information about the planning of and preparation for the questionnaire.

\section{Request supervision fees measure}

As last year, the request for the "supervision fee measure" is included in the Market Monitor. With your responses, the AFM assesses the 2017 supervision fees for your firm. This year, there is a possibility to choose the most appropriate measurement basis for your firm:

- The number of fulltime employees at December 31 of the previous year

- The average number of fulltime employees over the previous year. This average is calculated by adding the number of fulltime employees at March 31, June 30, September 30, and December 31 and dividing the obtained number by 4 .

More information is available in the Market Monitor.

Did your firm revoke its AFM-license in 2017?

Even if your firm revoked its AFM license in 2017, you are still obliged to complete the Market Monitor. In this case, it is sufficient to complete a number of questions, one of which is the measurement basis for supervision fees.

\section{Confidentiality of data provided}

We treat your data confidentially. This implies, among other things, that when we share data with third parties (for example in the form of publications of market analyses), it is never possible to trace data back to your firm. If the AFM shares information about the Market Monitor with the public or third parties via, for example, electronic news letters about intermediaries, this will only be on market level.

\section{Planning}

We divided all, approximately 7.500, intermediaries who participate in the Market Monitor in three groups. Your firm is in group [X].

From [DATE] the AFM opens the questionnaire digitally. You have five weeks to complete and submit the questionnaire. The deadline to complete and submit the questionnaire is thus [DATE]. A number of days in advance you will receive the information you need to login (one letter with your username and another letter with your password). With this data you can open, complete, and submit the questionnaire. 


\section{Preparation}

On our website www.afm.nl/marktmonitor-ab, you find more information on how to prepare for the Market Monitor. Among other things, you will find a printed version of the questionnaire on this website. Please note that this is a concept version and that the final questionnaire may contain changes.

Questions?

Would you still have questions after reading this information, you can contact 'het Ondernemerstoket'. 'Het Ondernemersloket' can be reached on working days from 10.00 until 17.00 via phone number 0800-6800 680 (free of charge) or by e-mail (ondernemersloket@afm.nl).

\section{Yours sincerely, \\ The Authority for Financial Markets}

Titles Initials Surname

Titles Initials Surname

\section{Usernameletter}

Subject: Invitation 2017 Market Monitor for intermediaries (with username)

Dear Sir, madam,

On [DATE] the Authority for Financial Markets (AFM) sent you a letter in which it announced the 2017 Market Monitor for intermediaries. With this letter, we request you to complete the Market Monitor.

The AFM divided the, approximately 7.500, intermediaries who participate in the Market Monitor in three groups. Your firm is in group [X].

How do you complete the Market Monitor?

From [DATE] you can complete the questionnaire via www.afm.nl/marktmonitor-ab. In order to complete the questionnaire you need data to login (a username and a password). Please find the username below. You will receive the password in a separate letter within a few days.

Username: [Username]

\section{Before which date do you have to complete the Market Monitor?}

The deadline for your group is [DATE]. It is possible to save your progress on the questionnaire.

You are obliged to complete the questionnaire. It is important you complete it timely, truthfully, and comprehensively.

\section{Questions?}

For more information, we refer to the instruction letter and www.afm.n1/marktmonitor-ab. 
Would you still have questions after reading this information, you can contact 'het

Ondernemersloket'. Het Ondernemersloket' can be reached on working days from 10.00 until 17.00 via phone number 0800-6800 680 (free of charge) or by e-mail

(ondernemersloket@afm.nl).

Yours sincerely,

The Authority forFinancial Markets

Titles Initials Surname

Titles Initials Surname

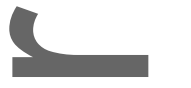

Password letter

Subject: Invitation 2017 Market Monitor for intermediaries (with password)

Dear Sir, Madam,

With this letter, we request you to complete the 2017 Market Monitor. In an earlier letter, you already received your username. In this letter, you receive your password.

Password: [Password]

It is obligatory to complete the questionnaire. It is possible to save your progress on the questionnaire.

You can complete the questionnaire from [DATE] via www.afm.nl/marktmonitor-ab. It needs to be submitted no later than [DATE].

Questions?

For more information, we refer to the instruction letter, letter with username and www.afm.nl/marktmonitor-ab.

Would you still have questions after reading this information, you can contact 'het

Ondernemersloket'. Het Ondernemersloket' can be reached on working days from 10.00 until 17.00 via phone number 0800-6800 680 (free of charge). 'Het Ondernemersloket' is also accessible yia e-mail: ondernemersloket@afm.nl.

Yours sincerely,

The Authority forFinancial Markets

Titles Initials Surname

Titles Initials Surname

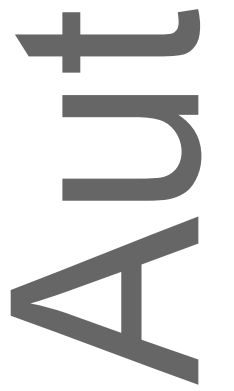

This article is protected by copyright. All rights reserved. 


\section{University Library}

\section{- M M N E R VA A gateway to Melbourne's research publications}

Minerva Access is the Institutional Repository of The University of Melbourne

Author/s:

Van Duin, SR;Dekker, HC;Wielhouwer, JL;Mendoza, JP

Title:

The Tone from Above: The Effect of Communicating a Supportive Regulatory Strategy on Reporting Quality

Date:

2018-05-01

Citation:

Van Duin, S. R., Dekker, H. C., Wielhouwer, J. L. \& Mendoza, J. P. (2018). The Tone from Above: The Effect of Communicating a Supportive Regulatory Strategy on Reporting Quality. Journal of Accounting Research, 56 (2), pp.467-519. https:// doi.org/10.1111/1475-679X.12205.

Persistent Link:

http://hdl.handle.net/11343/283871 